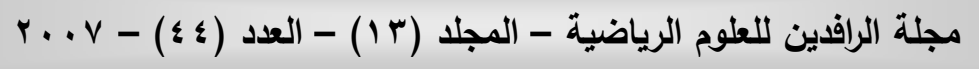

السلوك القيادي وعلاقته بالرضا عن العمل لدى مدرسي التربية

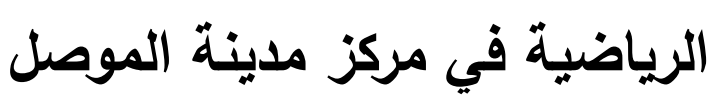

أ ـ م ـ ـ ـناظم شاكر الوتار السيد نقي حمزة جاسم

جامعة الموصل / كلية التربية الرياضية

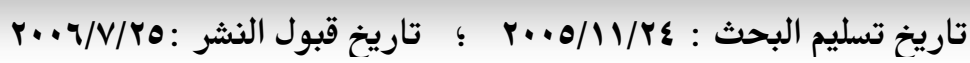

\title{
الملخص
}

تعـد الرياضــة أحــ المرتكزات الأسباسـية التـي تقوم عليهـا عمليـة النهـوض الـثامل

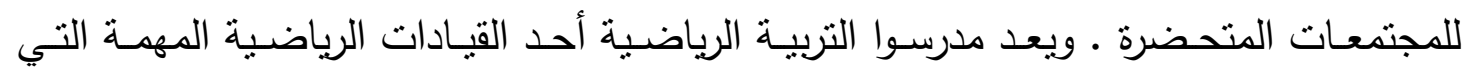

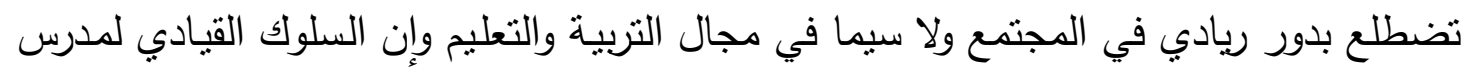

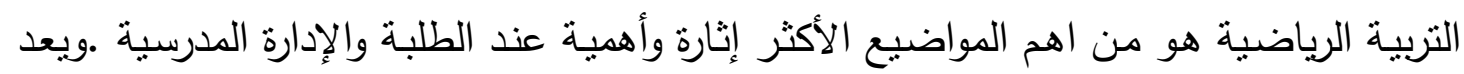

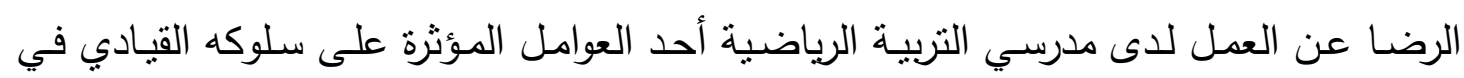

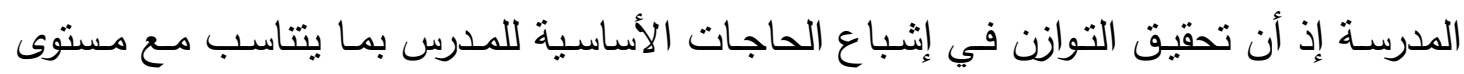
طموحه يعد مسالة في غاية الضرورة لتطوير العمل التربوي. وقد هدف البحث الحالي الى: ا ـ بناء مقياس الرضا عن العمل لمدرسي التزبية الرياضية . r. التعرف على العلاقة بين السلوك القيادي والرضا عن العمل لدى مدرسي التربية الرياضية في مركز مدينة الموصل .

وقد أفترض الباحثان مـا يأتي : لاتوجد علاقة ذات دلالة معنوية بين السلوك القيادي

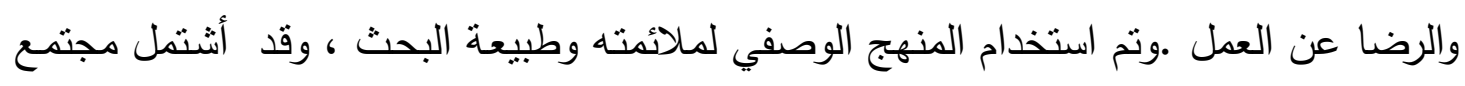

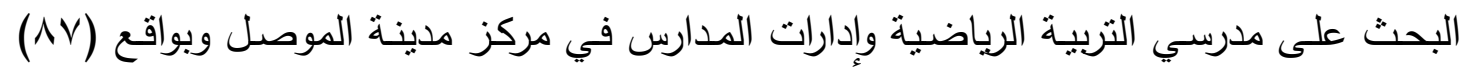
مدرساً و (اس) مدير مدرسة موزعين في الجانب الأيسر والأيمن لمدينة الموصل وقد قام الباحثان

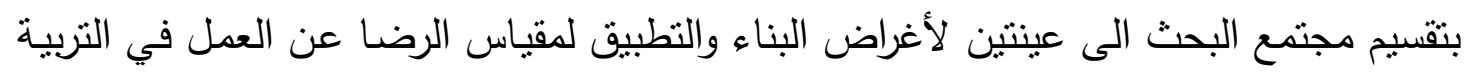

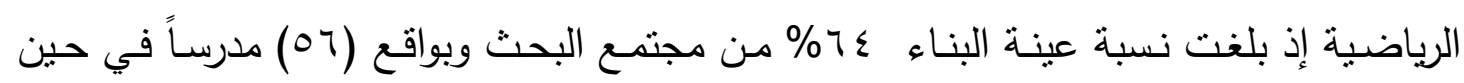

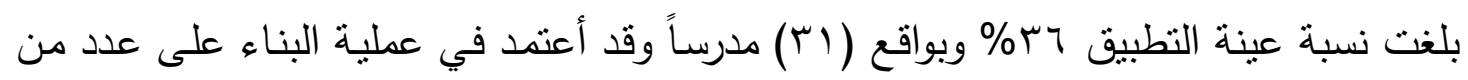


الإجـراءات العلميـة منهـا التحليـل الإحصـائي للفقرات بطريقـة الاتساق الـاخلي والمجموعـات


الخبراء وصدق البناء والصدق المرتبط بالمحك التجربة الاستطلاعية والثبات وقد تضمن المقياس

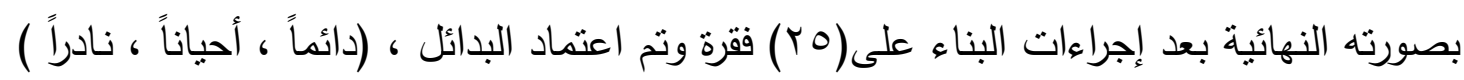

ومن أجل تعزيز القيمة العلمية للبحث وبعد أن أجرى الباحثان جميع الإجراءات العلمية

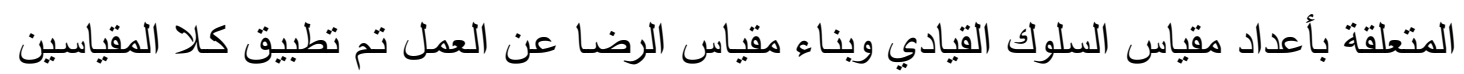
على أفراد عينة البحث حيث تم توزيع مقياس السلوك القيادي على مدراء المدارس في مركز

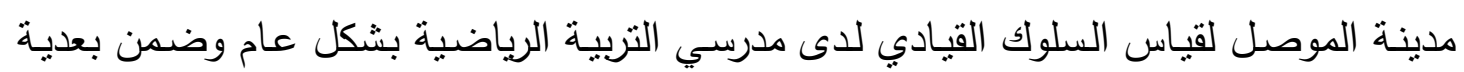

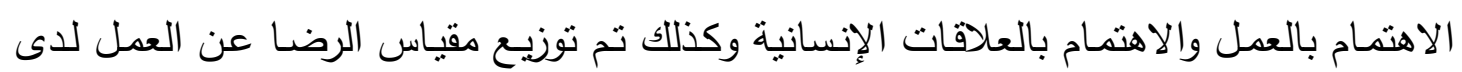

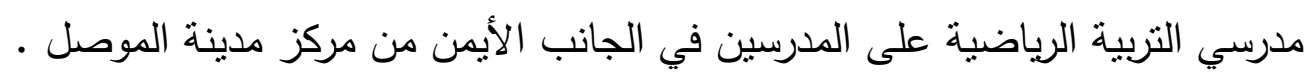
وقد توصل الباحثان الى عدد من الاستنتاجات كان من بينها : هناك علاقة ذات دلالة معنوية بين السلوك القيادي والرضا عن العمل لدى مدرسي التربية

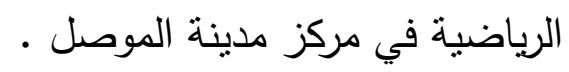
كما وأوصى الباحثان بما يأتي : ا ـ العمل على تتميـة درجـة الاهتمـام بالعمل والعلاقات الإنسانية بين مدرسي التربية الرياضية

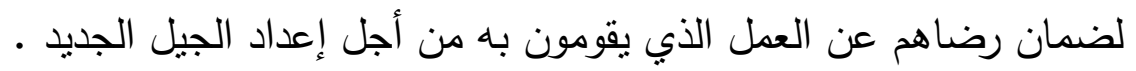

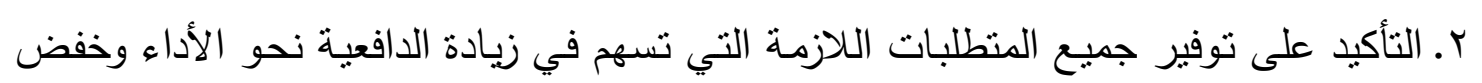

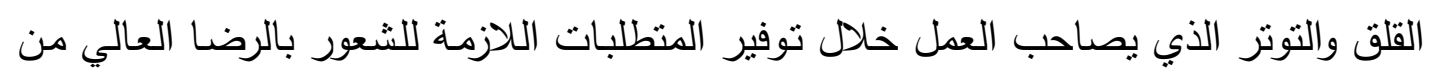

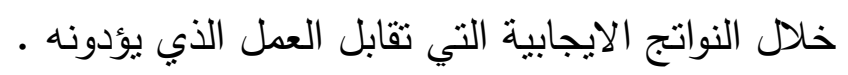




\title{
ABSTRACT
}

\section{Leadership Behavior and Its Relation to Job Satisfaction of Sport Education Teachers at the Mosul City Center}

\author{
Dr. Nadhim Al-Wattar \\ Mr. Naqi Hamza As-Sayya \\ Mosul University / College of Physical Education
}

Sport is considered one of the fundamental mainstays on which comprehensive revival of modern societies rests. Teachers of sports in this context are regarded as a significant part of the overall pioneering leadership that undertakes the leading role in the society in the field of sports education. Therefore, leadership behavior assumes more significance as it attracts the interests of both students and school administration .Job satisfaction, which is relevant to achievement in sport education this is because of the teachers of sport is one of the central factors affecting their leadership behavior in the school context. For realizing balance in the basic needs of teachers usually necessitates job satisfaction and job satisfaction is an indicator to the stability of man in his work environment .This thesis aims at a designing of a scale for job -satisfaction of sports' education teachers beside the preparation of a leadership behavior scale of sports education teachers. It also expounds the relation between leadership behavior and job-satisfaction of sports' education - of Teachers at Mosul city center The research hypothesis that have was no significant correlation between the leadership behavior and the job satisfaction. The researchers has adopted the descriptive approach for it best fits the research at hand. The research population consists of the teachers of sports and schools' administrations at the Mosul City Center. The number of the sample is 87 teachers and 63 schoolmasters located on both left and right sides of the City Mosul. Then this population has been subdivided into two samples to construct and implement the job -satisfaction scale in sports' education. The construction sample consists $64 \%$ embracing 56 teachers while the ratio of the implementation sample consists $36 \%$ embracing 31 teachers.

The construction process rests on several scientific procedures such as statistical analysis of items using internal consistency, extreme groups, etc. the construct of scales entailed objective specifications or characteristics of the scale which included experts' validity, construct validity, criterion related validity besides a number of exploratory experiment and reliability. So the final draft of the scale contains 25 items while the choice alternatives encompass (always, sometimes, rarely). 
To cement the scientific quality of the research and after streamlining all the scientific procedures relevant to the scale of leadership behavior and the construction in full of the job -satisfaction scale, both scales have been applied to the research sample when the leadership behavior scale has been handed round the school masters' sample to measure the leadership behavior of sports' education teachers in general and within its two dimensions of interest in the job and interest in humanities. The job -satisfaction scale on the other hand, has been distributed among teachers on the right side of Mosul City Center.

\section{المقدمة وأهمية البحث}

يميل العديد من المنظرين في التربيـة الرياضية الـى النظر للقيادة من خـلال طبيعة المواقف والأنشطة والأدوار التي يقوم بها القائد ، والتي لن تخرج عن كونها ضبط ونيافين وتوجيه واثارة سلوك واتجاهـات الآخرين فحسب في حين ان القيادة تعني بمضمونها العلدي الدقيق القدرة

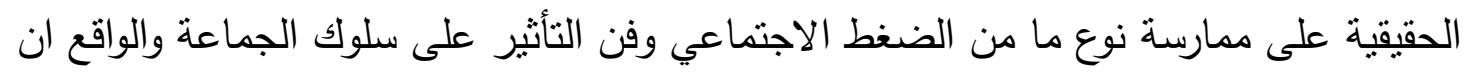

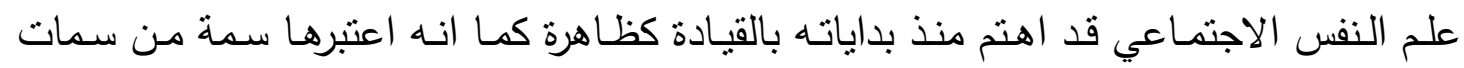

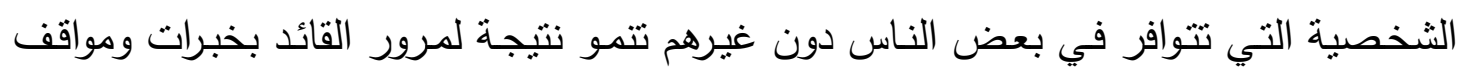

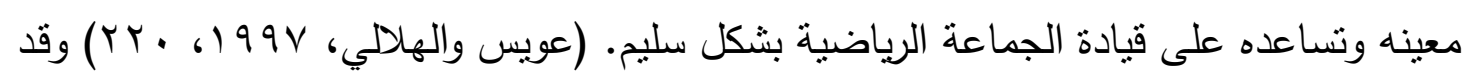

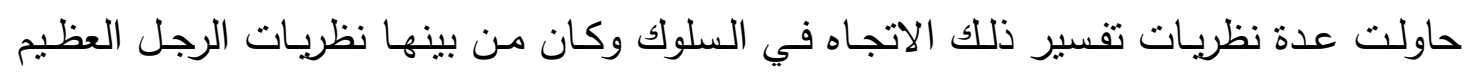

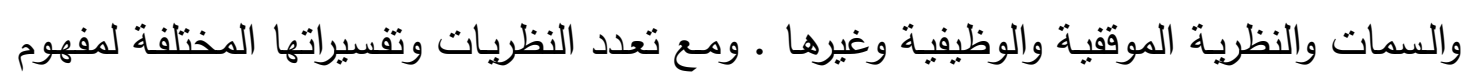



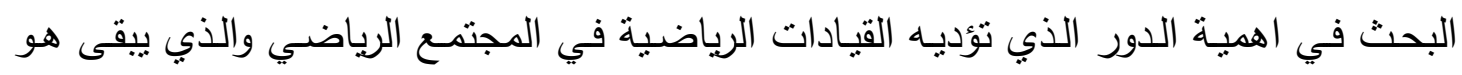



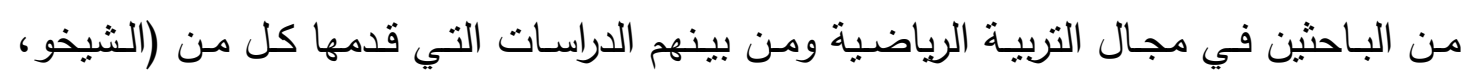

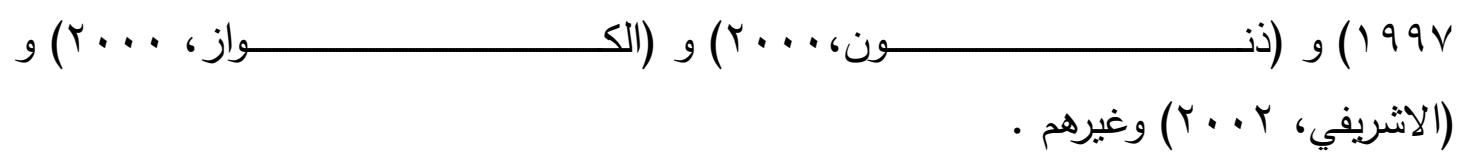

ويعد مدرسو التربية الرياضية احد القيادات الرياضية المهمة التي تضطلع بدور ريادي





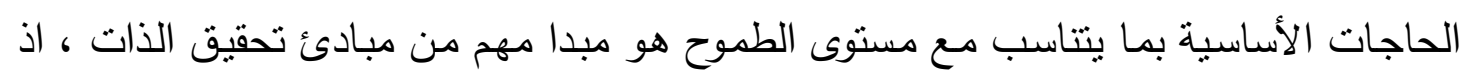

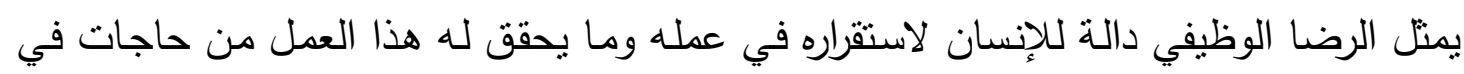

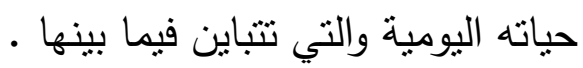


وبنـاءً على مـا تقدم وانطلاقـا مـن المفـاهيم الأساسية للسلوك الإنساني والاجتمـاعي للرياضة والذي يتضمن تباينا ملحوظا بطبيعة المتغيرات التي تؤثر في تشكيل العلاقات الدختلفة



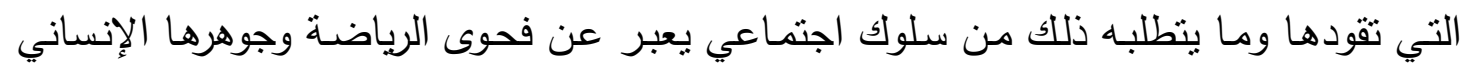

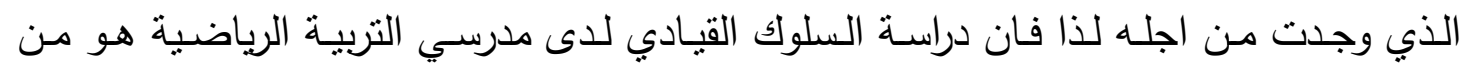

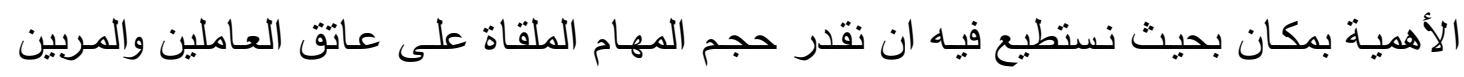

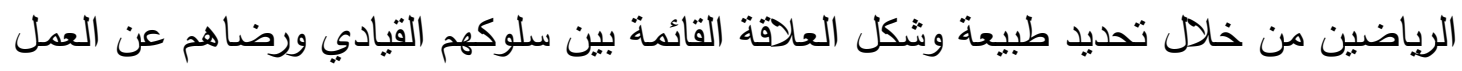

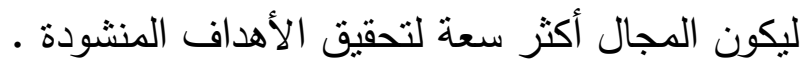

مشكلة البحث

تعد القيادة احلـ المقومـات المهــة في التأثثر على سلوك الآخرين وتوجيـه طاقاتهم

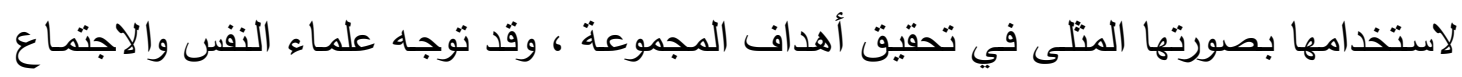
منذ فترة طويلة الى دراسة المجموعات الإنسانية ودورها في تكوين شخصية القائد الناجح وتحديد

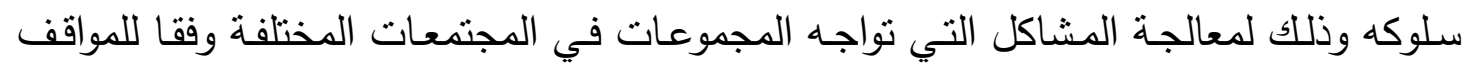
والظروف المختلفة .

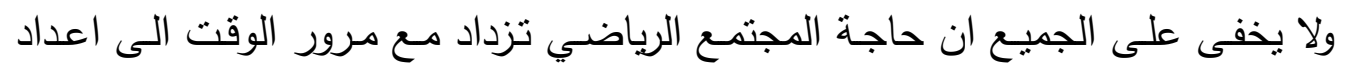

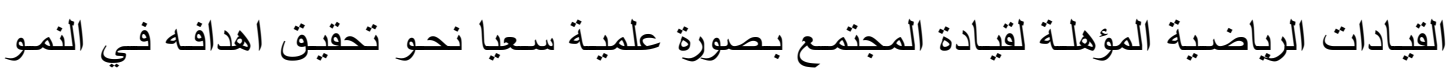

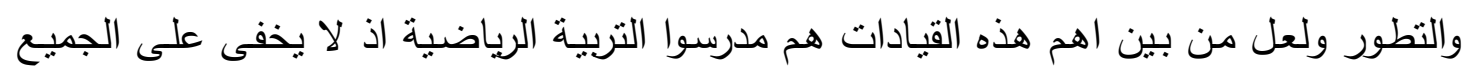

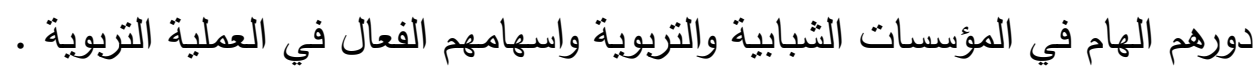

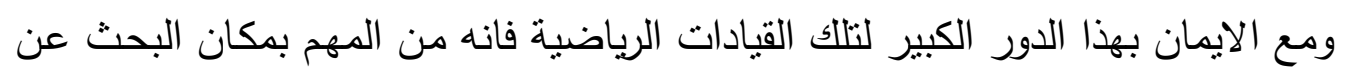

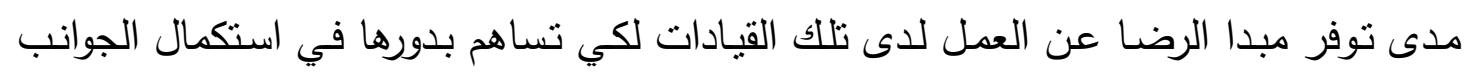

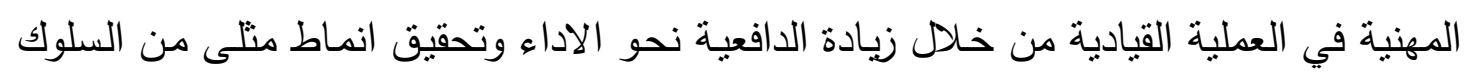

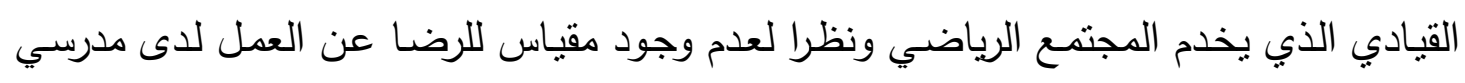

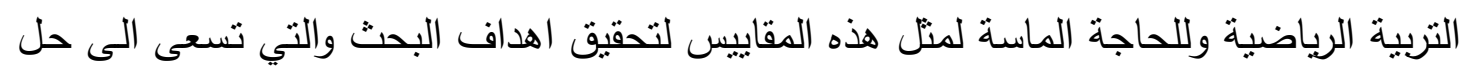

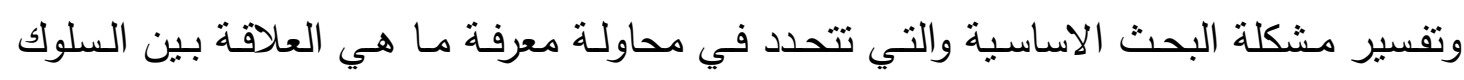

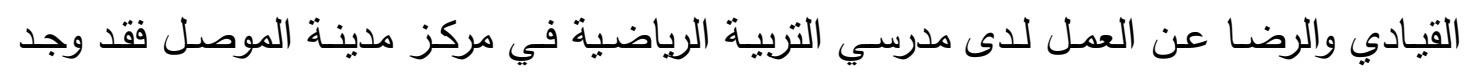

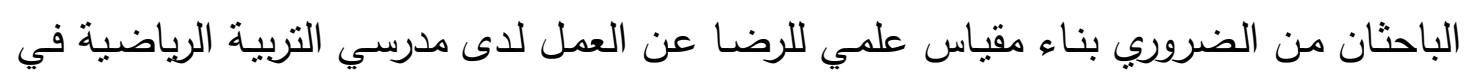

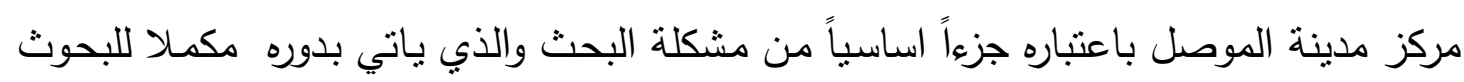

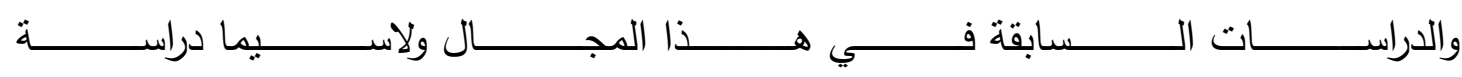

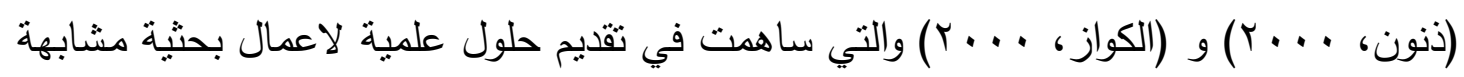


سـاعدت الباحثنان في اختيـار الوسـائل المناسبة لتحليل واختيار مشكلة البحث اذ ان ظهور

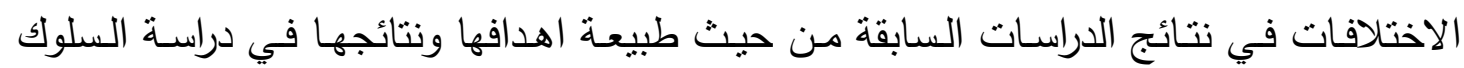

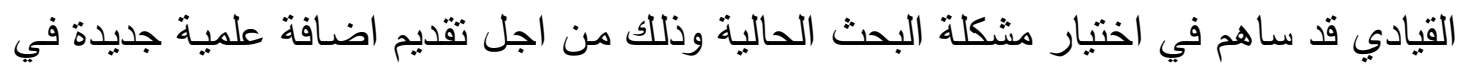
ميدان العمل الرياضي في القطر ولاسيما في مجال علم النفس الاجتماعي والرياضي. أهداف البحث ا ـ بناء مقياس للرضا عن العمل لمدرسي التربية الرياضية . r. التعرف على العلاقة بين السلوك القيادي والرضـا عن العمل لدى مدرسي التربية الرياضية

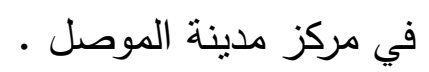
فرضية البحث ا ـ لا توجد علاقة ذات دلالة معنوية بين السلوك القيادي والرضا عن العمل لدى مدرسي التربية الرياضية.

\section{مجالات البحث}

- المجال البشري: مدرسو التربية الرياضية ومدراء المدارس في مركز مدينة الموصل - المجال المكاني:المدارس الإعدادية والمتوسطة في مركز مدينة الموصل

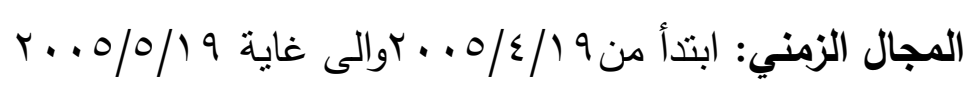
تحديا المصطلحات 1-السلوك القيادي :

- عرفه (جردات، ب1911): بانه ممارسات وفعاليات يكون فيها استخدام القائد للسلطة او منحه

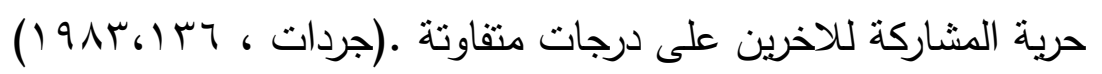
- عرفه (الثهابي، ج1911): بانه الأسلوب الذي ينتهجه القائد الإداري ويدرك من قبل تابعيه

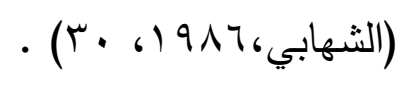

\section{التعريف الإجرائي للسلوك القيادي :}

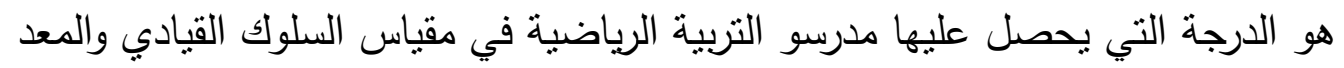

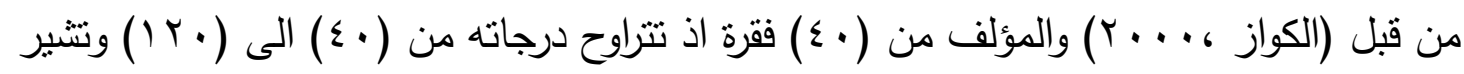
الدرجة العليا على المقياس الى قدرة المدرس على السلوك القيادي ويشمل ذللك بعدي العلاقات الانسانية والاهتمام بالعمل والاهتمام بالعلاقات الانسانية ويقاس من وجهة نظر ادارة المدرسة. 


\section{r-الرضا عن العمل:}

- عرفه (العدوان واحمد ، 09991) : بانه شعور يحمله الفرد نحو وظبفته او حالة نفسية نحو

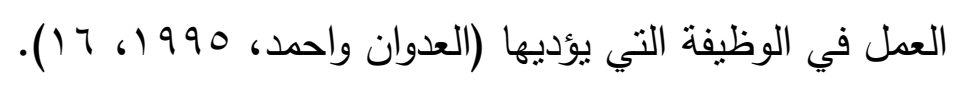

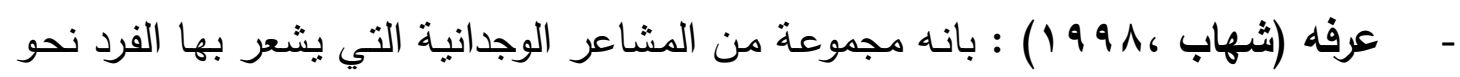

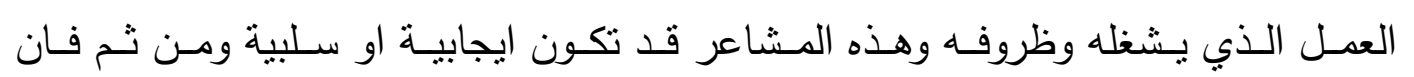

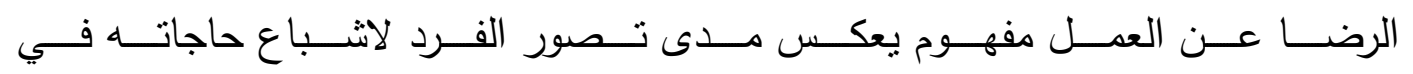

$$
\begin{aligned}
& \text { العمل (شهاب ، \& ع 1991) (1). } \\
& \text { التعريف الاجرائي للرضا عن العمل: }
\end{aligned}
$$

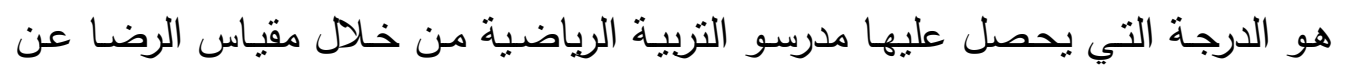

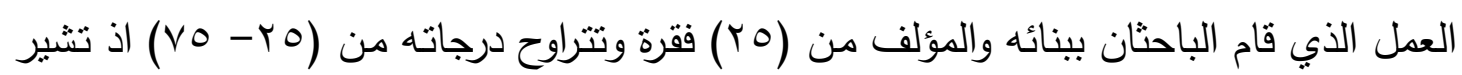

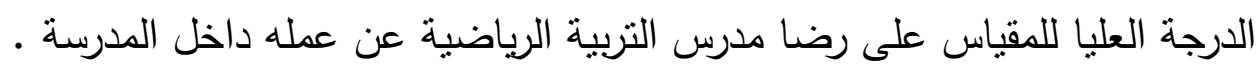

\section{r- نظريات السلوك القيادي ( Leader Behavior Theories)}

\section{نظريات سلوك القائد}

\section{- سلوك القائد في مجال استعمال الحوافز :}

يستعمل القائد حوافز ايجابية وحوافز سلبية ، والحوافز الايجابية تتمثل بمحاولته التأثير

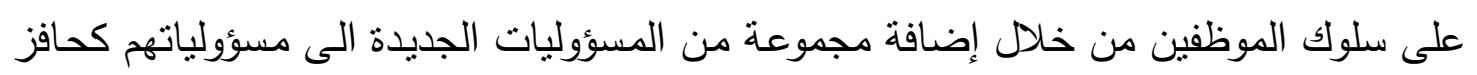

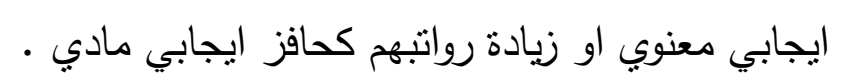

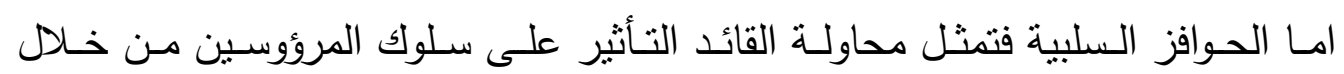
تجريدهم من مسؤولياتهم او التلويح بفقدان الوظيفة في حالة التقصير وهذا يعد حافزا معنويا سلبيا او ان يخفض راتب المرؤوس بمقدار معين وهذا يعد حافزا ماديا سلبياً.

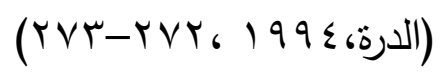

- سلوك القائد في مجال استعمال السلطة : تسير هذه النظرية باتجاه الاهتمام بالعمل والعلاقات الإنسانية في ضول ضوك استخدام القائد

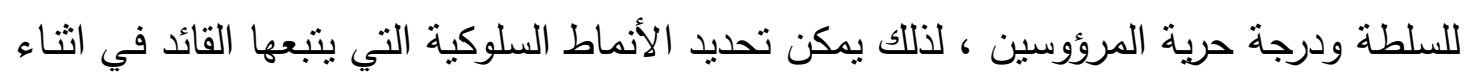

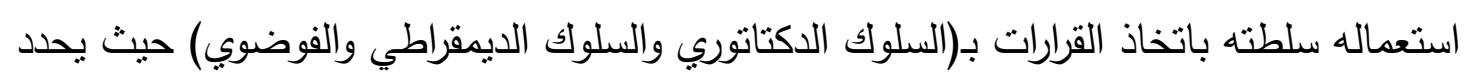
(تنن بام وشمدت) (Tanninbaum \& Schmidt, 1985) سبعة انماط للقيادة على محور 
منصل يتراوح بين القائد الدكتاتوري (المركزي) الذي يهتم بالعمل ويتخذ القرار بنفسه، ونمط القائد

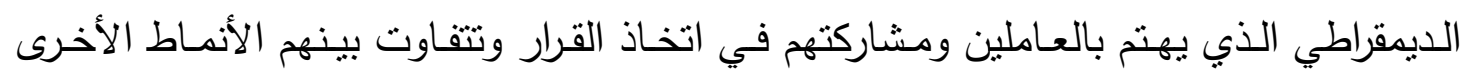
وكالاتي : 1 - قائد يصنع القرار ويعلنه .

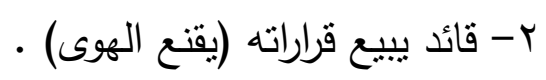

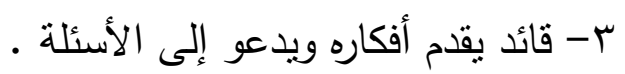

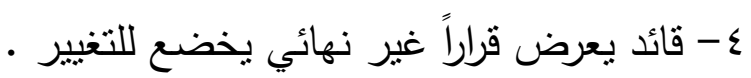

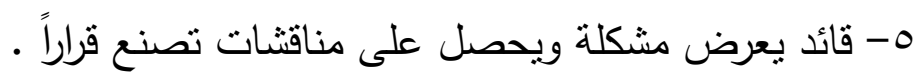

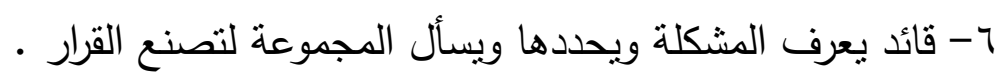

(Tanninbaum \& Schmidt, $1985:$ 104)

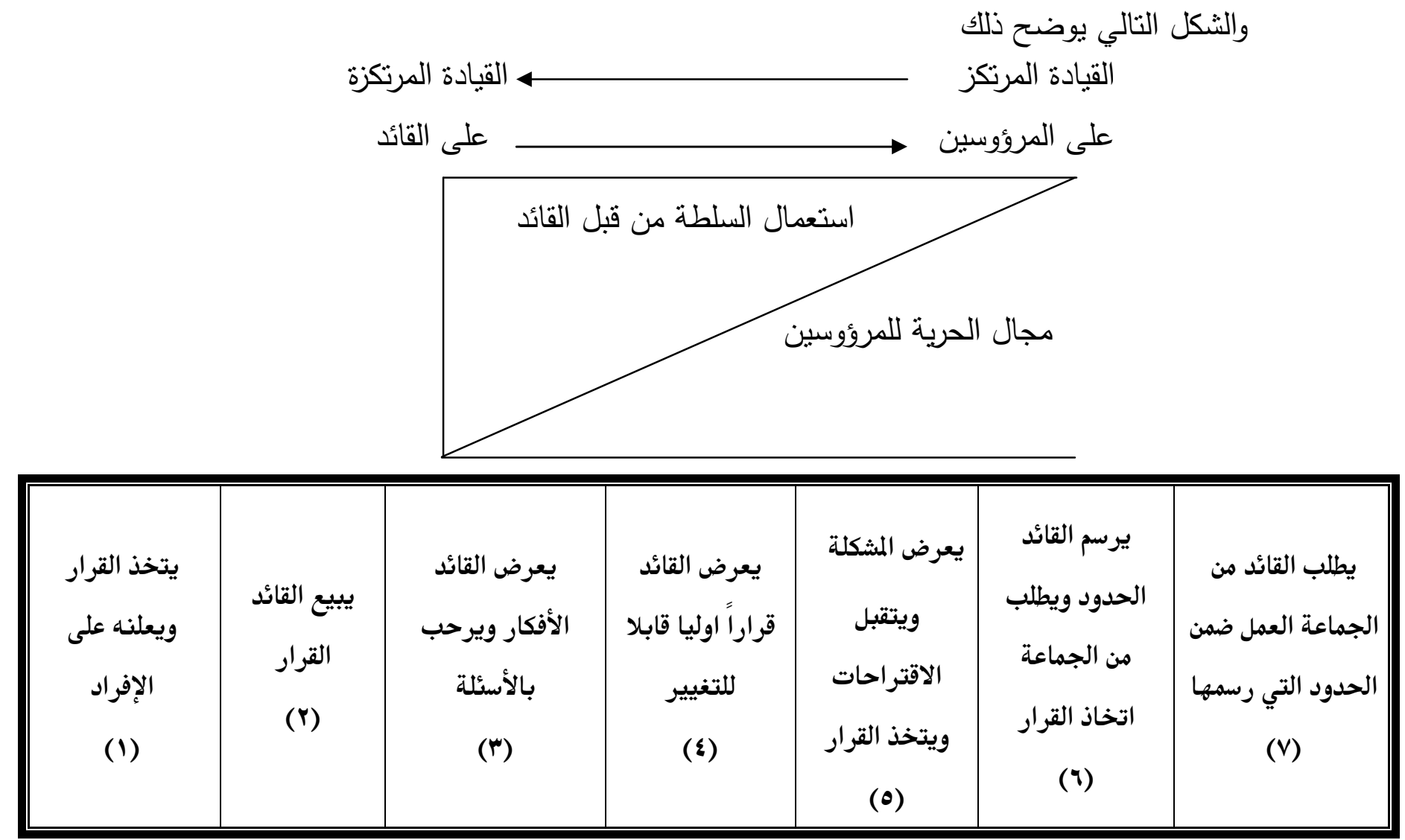

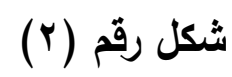

السلوك القيادي في مجال استعمال السلطة (كلادة، 9 ( 979 ، 9 ) - سلوك القائد في مجال العمل والعاملين : 
لقد انعكس المدخل السلوكي للقيادة في بدايته من خـلال دراسـات جامعة اوهايو ، اذ بدأت هذه الدراسات سنة 9 أو وتبنت سؤالا (هل يمكن وصف سلوك القائد بأنه سلسلة واحدة) وقد وصفت هذه الدراسة الكيفية التي يقيم بها القائد نشاطاته وحاولت إعطاءه أسماء وتعريفات .

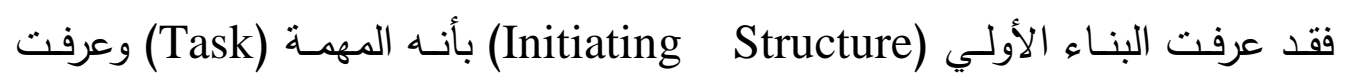

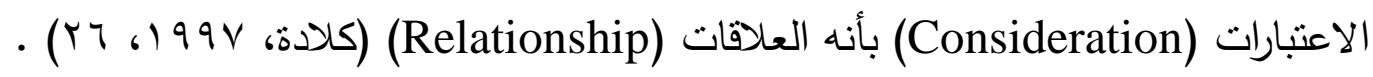
وأثنارت نتائج الدراسات إلى ان المهمة والعلاقات الإنسانية هما ليستا سلسلة واحدة تبدأ

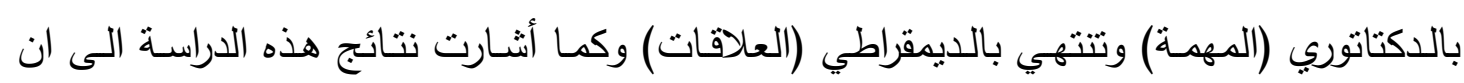
هناك سلوكين او نمطين أساسين للقائد :

Initiating Structure ) سلوك يتمثنل في وضـع هيكليـة العمل او الاهتمـام بالعمل (Behavior

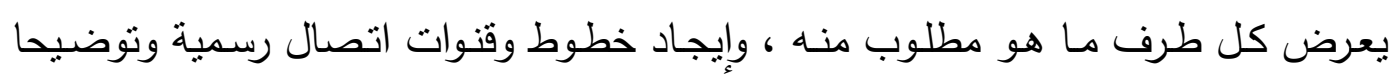
فضلاً عن تحديد كيفية انجاز المهام والإعمال .

والصفة الغالبـة على هذا السلوك هي اهتمـام القائد بتوجيـه المرؤوسين بغيـة تحقيق الأهداف التتظيمية وانجاز الإعمال . r- سلوك يتمثل بالعاملين (Consideration Behavior) ينطوي هذا السلوك على الاهتمام

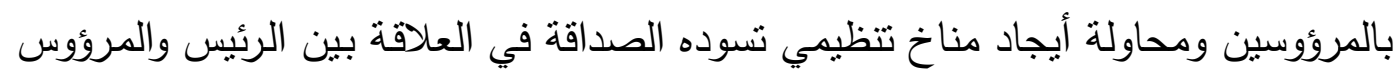

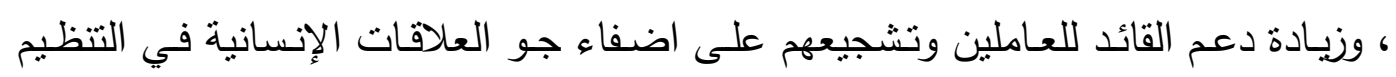

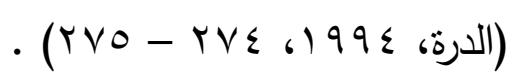
السلوك القيادي في الرياضة : في ضوء العديد من الدراسات السابقة تم التوصل الى ان القائد الرياضي الناجح يتميز

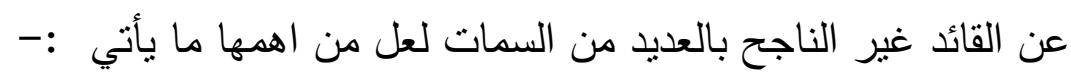
يعد التحكم في الانفعالات من الأهمية بمكان للقائد الناجح حتى يسنطيع إثباع الهدوء

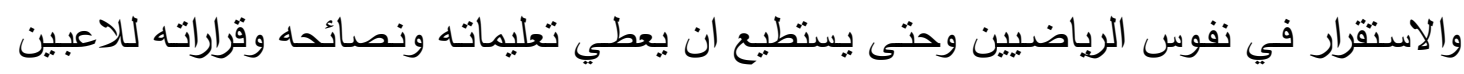

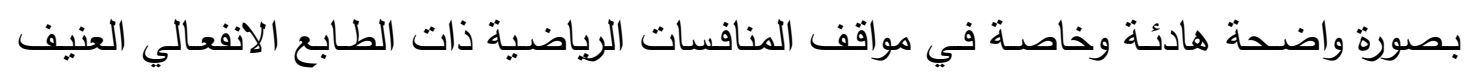
والضغوط النفسية العالية . - التناغم الوجداني والتعاطف (المشاركة الاجتماعية) : 
يقصد بالتتاغم الوجداني (Empathy) احساس وادراك القائد لما يحس به الرياضي لفهم

انفعالاته وتقديره لما يعانيه .

- القدرة على اتخاذ القرار : -

أي قدرة القائد على سـرعة اتخـاذ القرار وخاصـة في المواقف المنافسة المتغيرة التي لـي



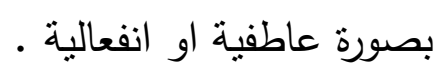

- الثقة بالنفس : - n

ان القائد الذي يتميز بثقته في نفسه وفي قدراته وفي معلوماته ومعارفه وخبراته يكتسب

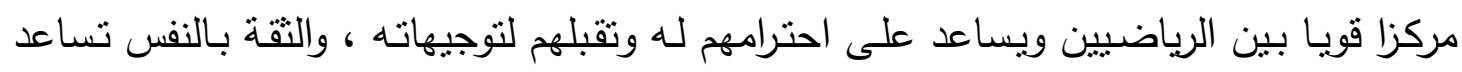

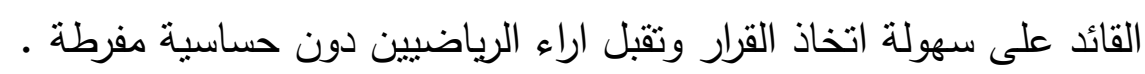
- تحمل المسؤولية : - ت ت

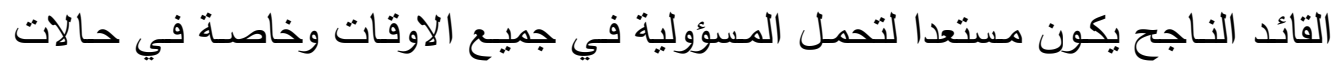

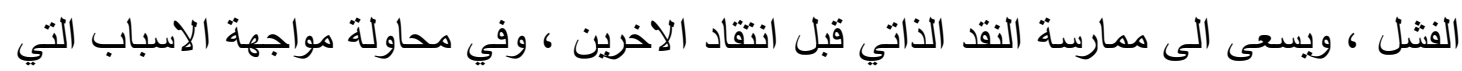

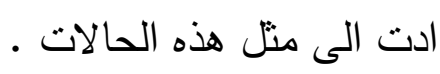
- الإبداع - (1) -

ان القدرة على الابتكار واستخدام العديد من الوسـائل الحديثة والمبتكرة اثناء التدريب الرياضي ، وكنلك النتكيل المتتوع للبرامج التنريبية والقدرة على إبراز انواع متجددة ومبتكرة في لإني مجال عملية التدريب الرياضي تعد من بين اهم العوامل التي تظهر قدرة القائد على الإبداع. - المرونة : -

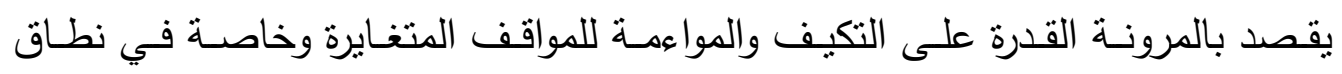

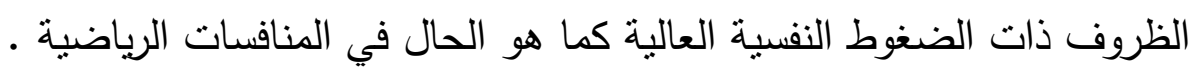
- الطموح : -

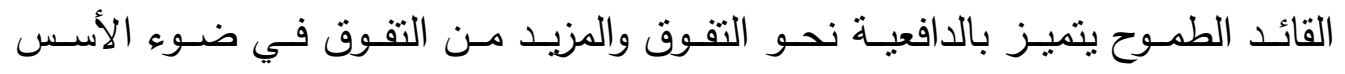

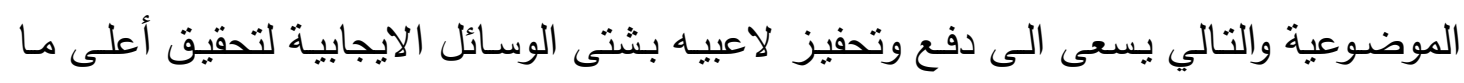

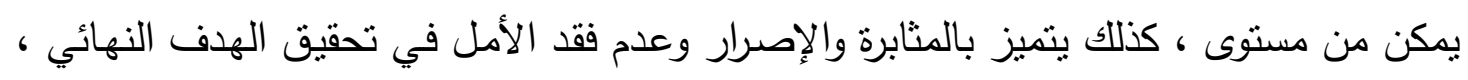
ولا بستسلم بسهولة ويسعى نحو تطوير نفسه وتطوير قدراته ومعلوماته.

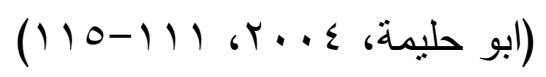




\section{نظريات الرضا عن العمل}

\section{- نظرية ماسلو Maslow Theory:}

ان النظريات التي تتاولت موضوع الرضا عن العمل قد استتدت في معظمها على نظرية

تدرج الحاجات لابراهام ماسلو (Tـ (1) والذي يعد أسـاس نظريات الدافع الإنساني ، اذ أثـار ماسلو الى ان السلوك يتحرك بسبب وجود حاجات غير مشبعة الى حد ما فان الفرد يندفع الى

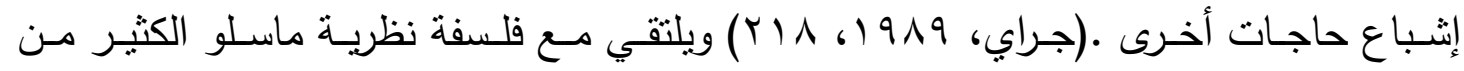
الباحثين في ميدان الدراسـات السلوكية فها هو ماجر يجور (Megregor) في أوائل الستينات يأخذ النظرية التي قدمها ماسلو عن تدرج الحاجات والدوافع الإنسانية ليقدمها للباحثين والدارسين لتصبح نظرية ماسلو بعد ذلك من اكثر النظريات شيوعا وإقبال .

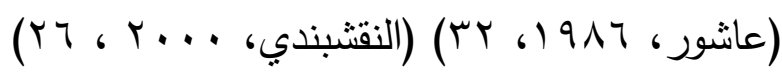

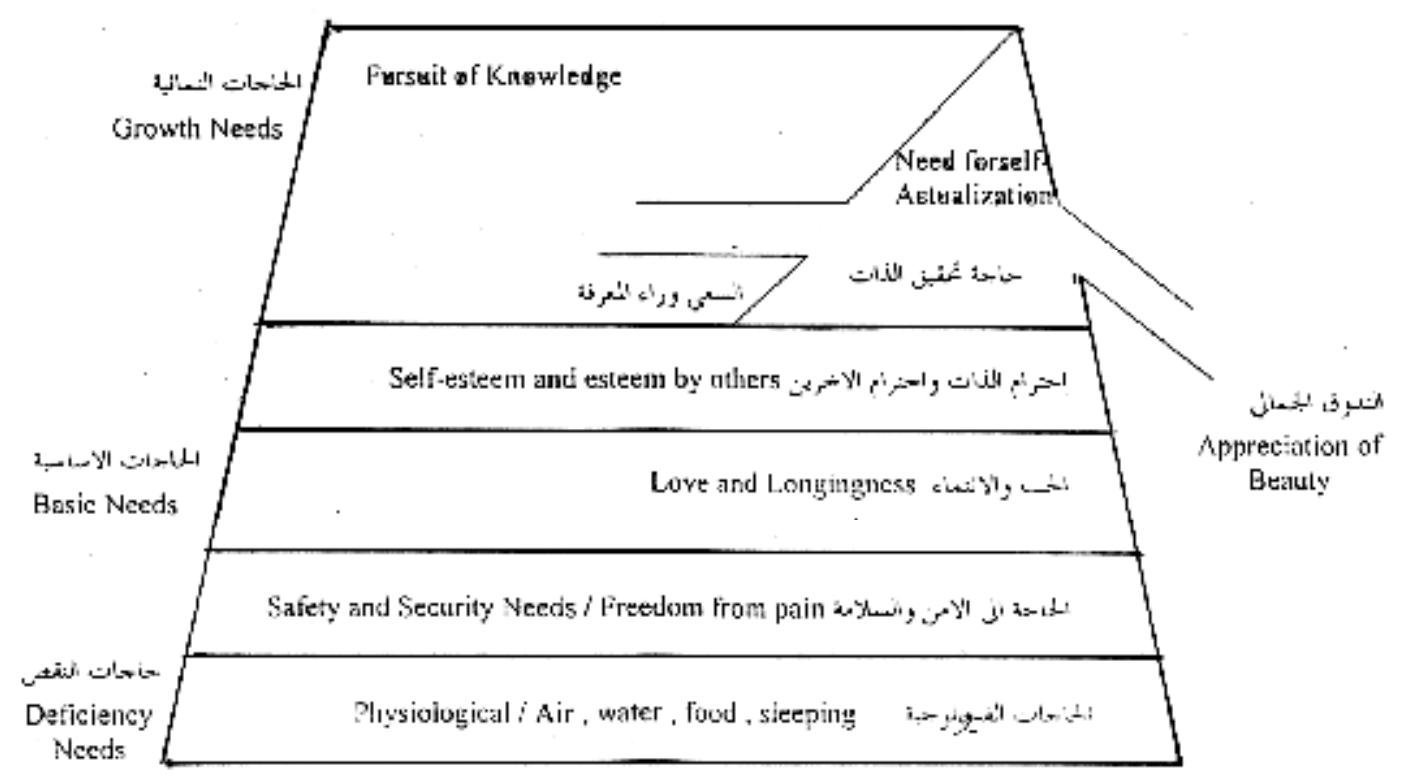

النسث والتنظيم الهرمي للحاجات عند ماسلو

Two-factor Theory نظرية العاملين (او العنصرين) - 
قام فرديرك هيرزبرج (F . Herzberg) وزميلاه فوسنر وسنايدرمان في الخمسينات

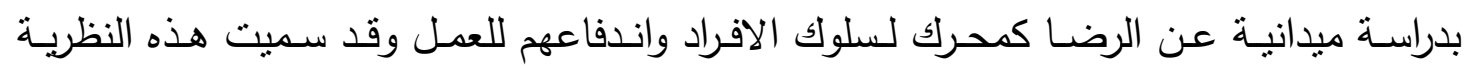

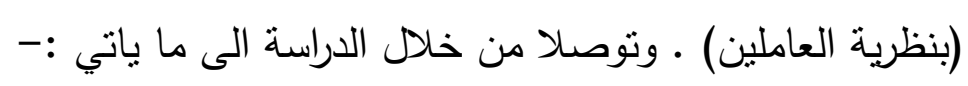

1. ان العوامل التي تخلق لدى الفرد شعورا بالرضا العالي عن الوظيفة او العمل تسمى بالعوامل

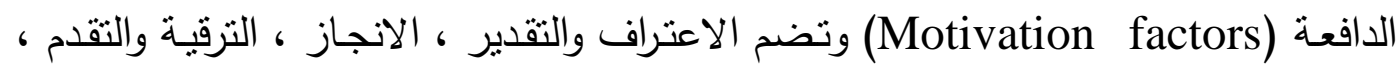

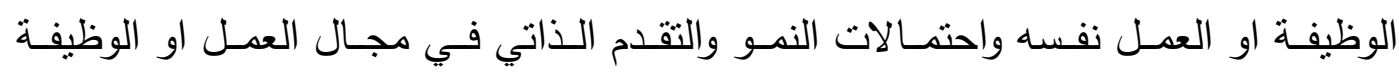
والمسؤولية.

r. ان العوامل التي تسبب للفرد شعورا بالاستياء الثديد من الوظيفة او العمل او المحافظة

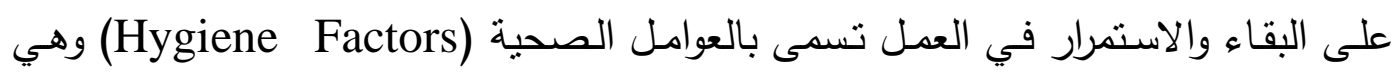

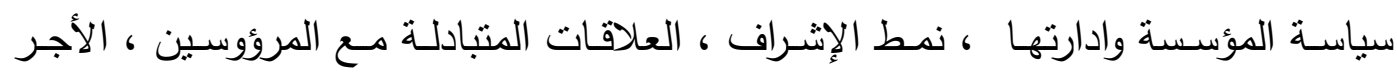

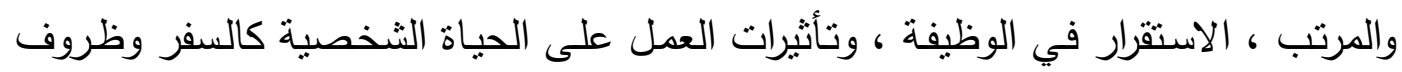

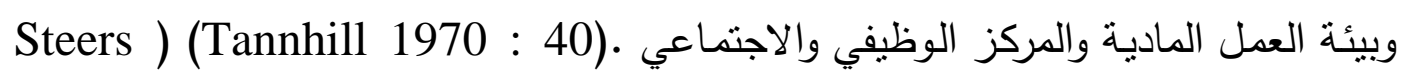

$$
\text { (1983: } 484
$$

\section{- نظرية المساواة Equity Theory -}

تعد نظرية المساواة من اكثر النظريات قبولا وأكثرها أحكاما هي تلك التي صاغها ادمز

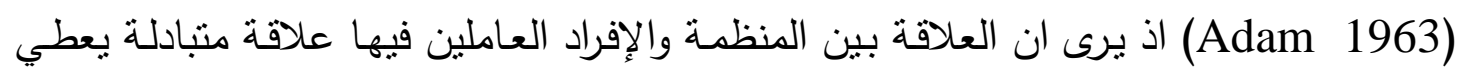
فيها العاملون مجموعة من المدخلات Inputs وتتضمن مثلا المستوى التعليمي للفرد ، وخبراته ، وقدراته ، وعمره والجها الذي يبذله في العمل ويحصل الفرد من المنظمة مقابل هذه المدخلات

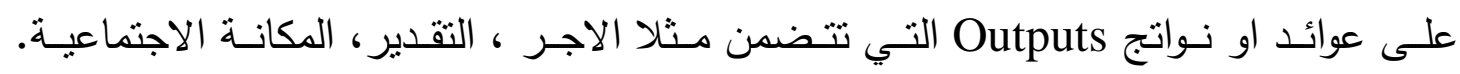

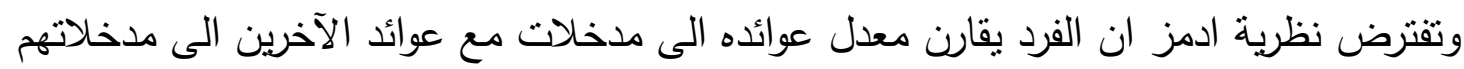

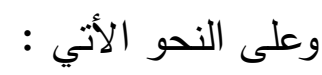

مدخلات الفرد

يوضح مقارنة معدل عوائد الفرد الى مدخلاتهم مع عوائد الاخرين الى مدخلاتهم حسب افتراض ادمز

(Lorenz 1997 : 324)

عxpectancy Theory - نظرية التوقع 
تختلف نظرية التوقع عن نظريات الرضـا عن العمل الأخرى في أنها تحاول الاهتمام

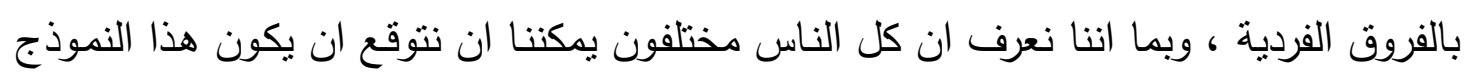

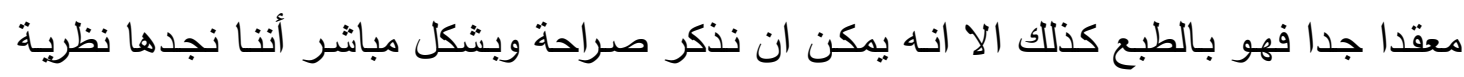

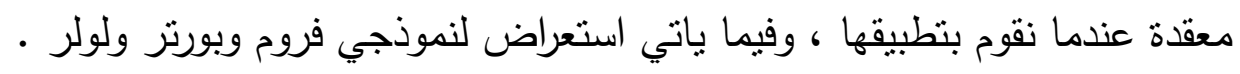

\section{أ- نموذج فروم Vroom Model}

يعد نموذج (فروم) وتعديلاته لاحقا من قبل (هاوس)و (وهبة) من النظريات الحديثة في

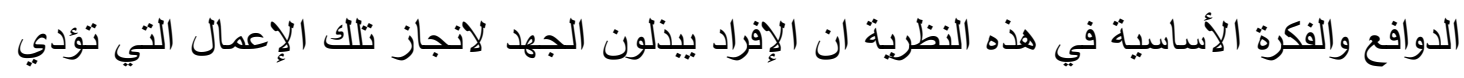

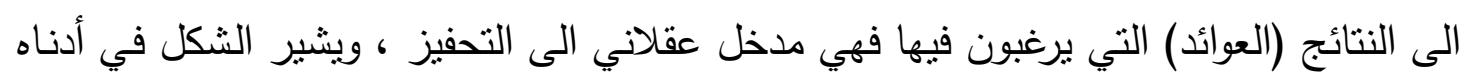
الى العلاقات الأساسية في هذه النظرية .

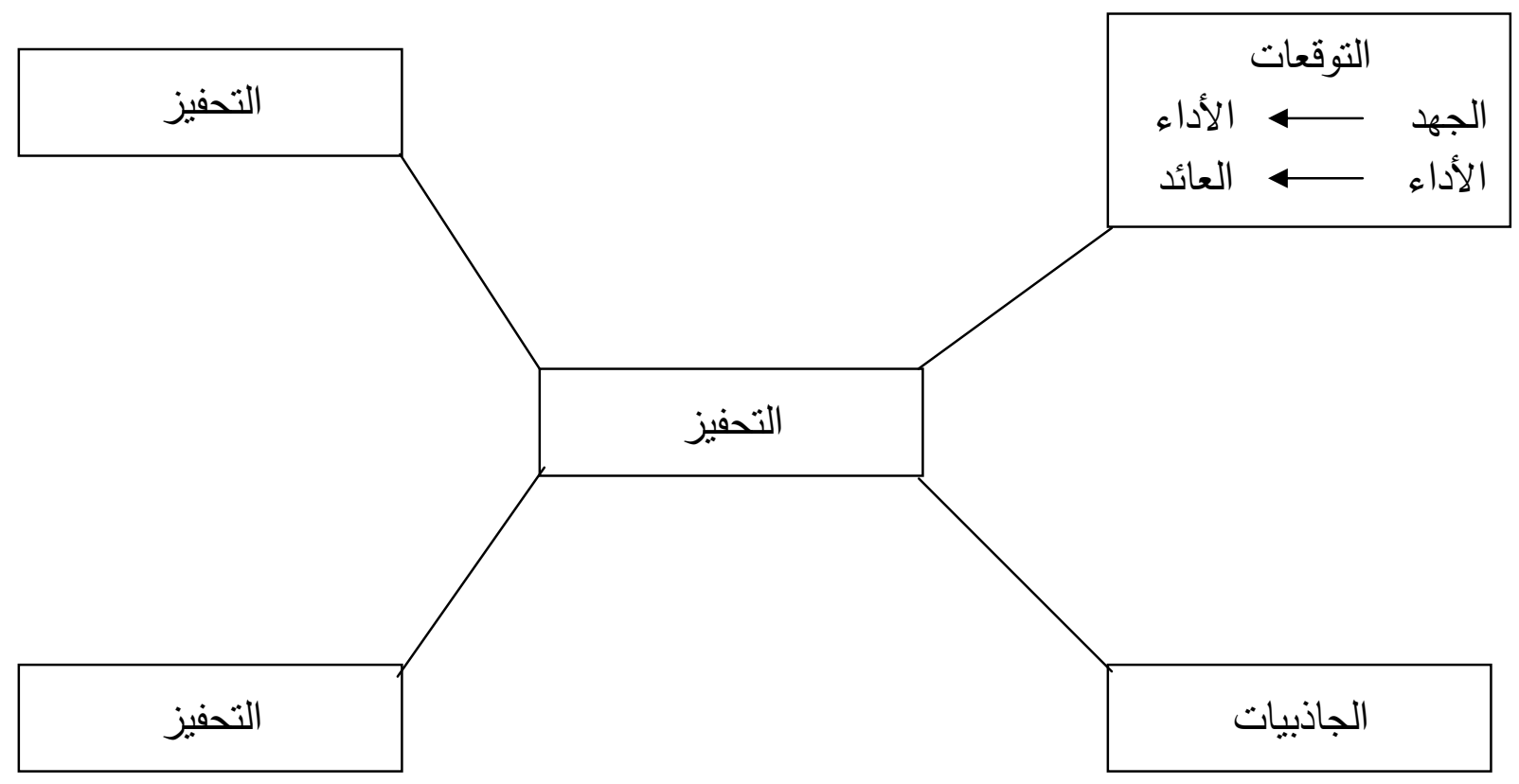

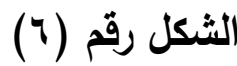

يوضح المفاهيم الأساسية في نظرية فروم (التوقع)

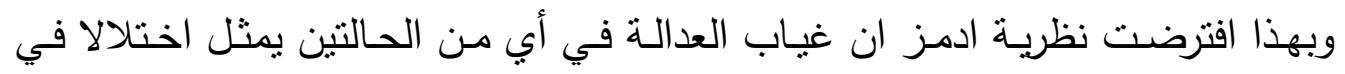

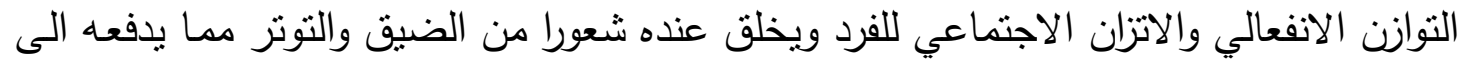

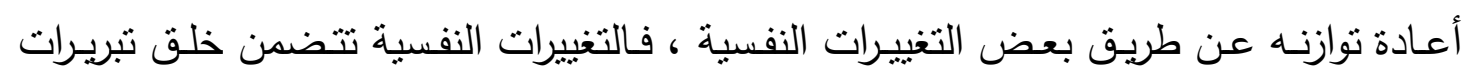

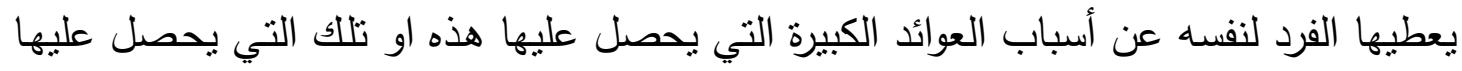
الآخرون ، اما القيام بتصرف او فعل ملموس فقد يتضمن محاولة تغير مدخلات الفرد (مجهوده

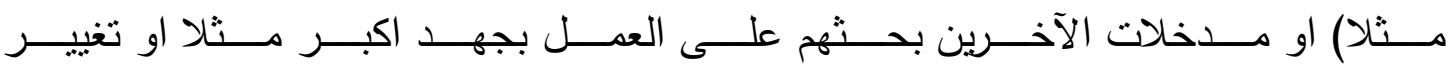






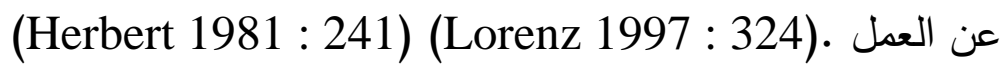
ب- بموذج بورتر ولولير (Porter and loler Model) يعد نموذج بورتز ولولر (971 (1) توسيعا وإكمالا لنظرية التوقع اذ بينا ان الجهد الذي يبذله الفرد في العمل يعتمد على القيمة التي يراها الفرد في المكافأة المتوقعة وعلى احتمالية تحقيق الككافأة ووقوعها في حال بذل الجهد وقد اكد بورتر ولولر من خلال أنموذجهما أهمية الدور الذي تلعب المكافأة الداخلية والخارجية في نظرية التوقع في الرضا عن العمل وكما

هو موضح في الثكل رقم (V)
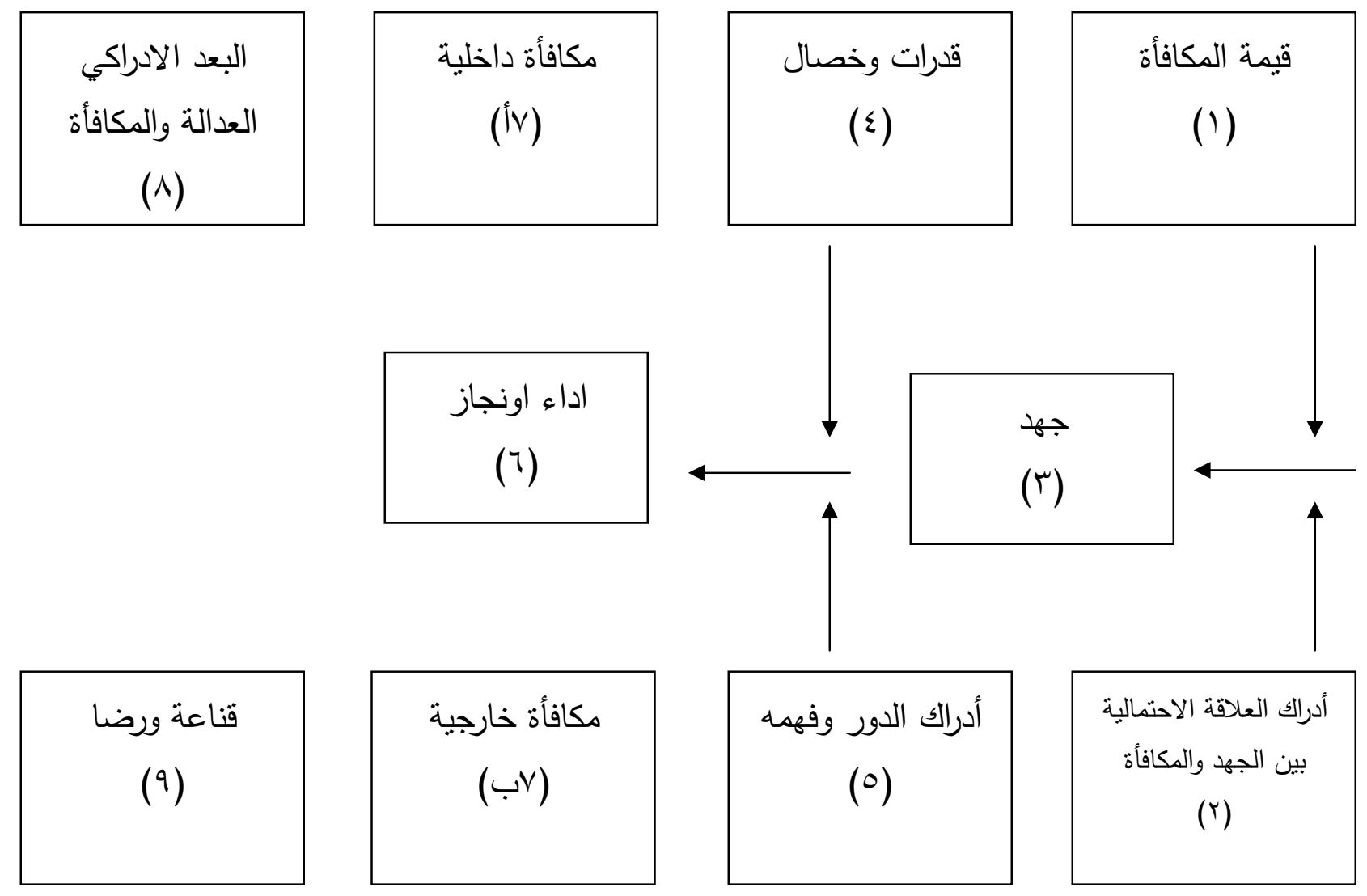

(V) الثكل رقم

يوضح أنموذج بوتر ولولير

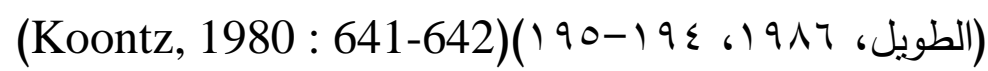


استخدم الباحثان المنهج الوصفي لملاءمته لطبيعة البحث .

\section{مجتمع البحث}

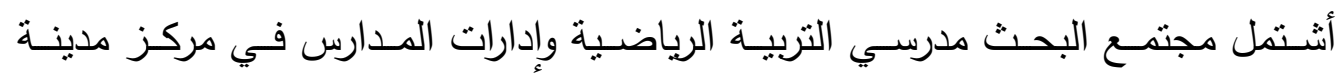
الموصل وبواقع (^V) مدرساً و (T/) مدير مدرسة موزعين في الجانب الأيسر والأيمن لمدينة

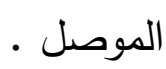

وقد قام الباحثان بتقسيم مجتمع البحث إلى عينتين لأغراض البناء والتطبيق لمقياس

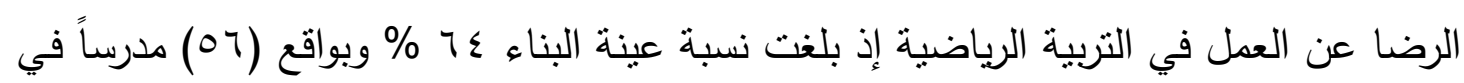

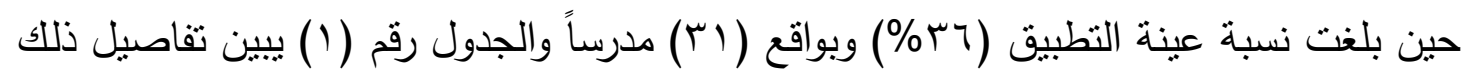

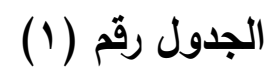

يبين مجتمع البحث وأعداد المدرسين عينة البحث و التطبيق و النسبة المئوية لكل منهم

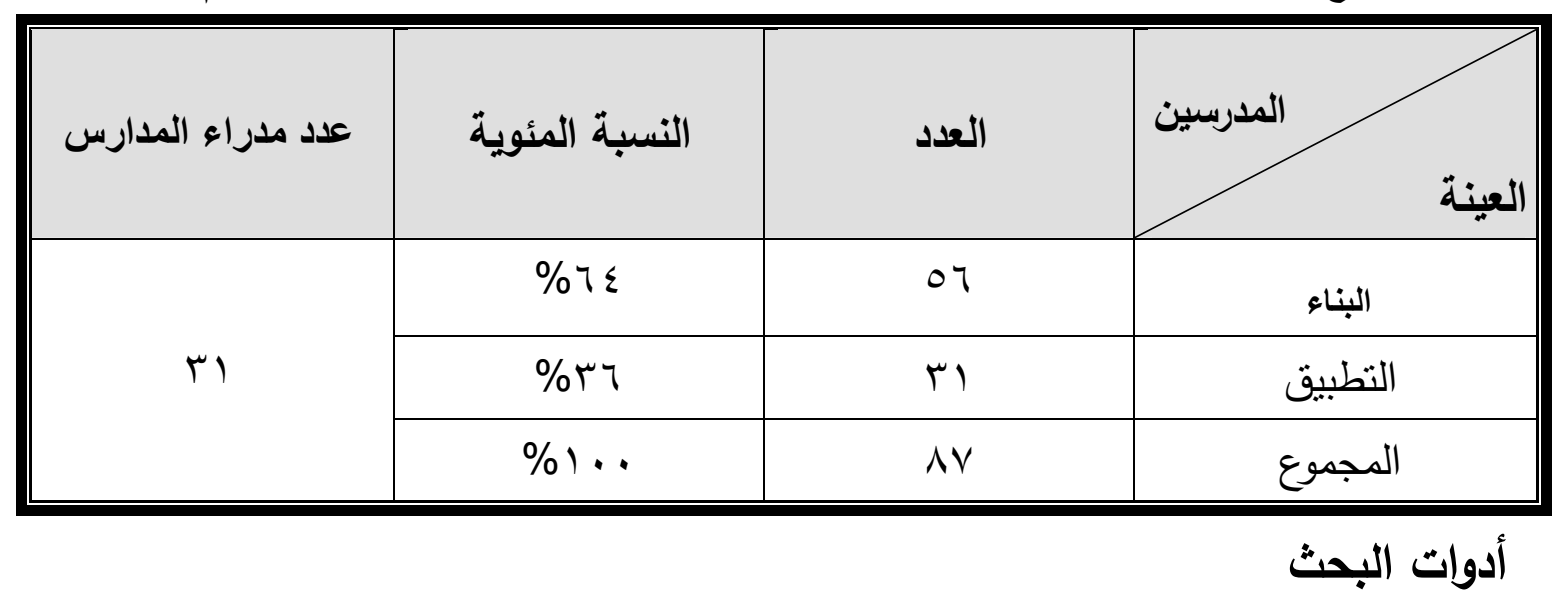

1- مقياس السلوك القيادي :

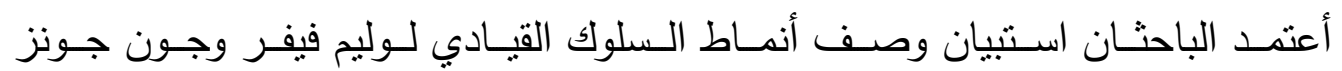

(W. Piffer \& Jones leadership questionnaire) .

الذي أعده بالعربيـة وطوره ( محمد إسـماعيل يوسف ) ) واسـتخدمته عصمه فروقـة

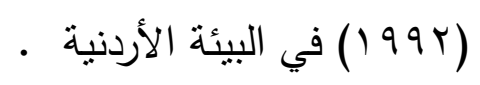

يتكون المقياس بالأصل من (•؛) فقرة خصص (•r) منها لقياس مدى اهتمام العدداء

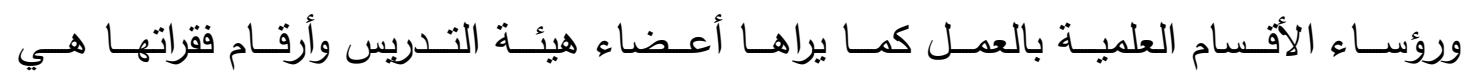

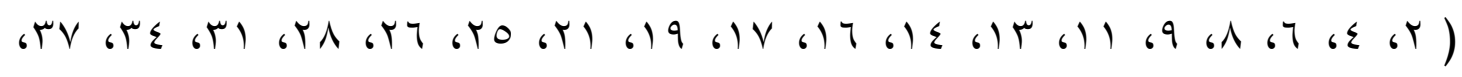


^r، • ع، ) ، وخصصت ( • (Y) فقرة لقياس مدى الاهتمام بالعلاقات الإنسانية وكانت أرقامها (T) דr، 9 9) ، وتتم الاستجابة باختيار إحدى البدائل الأربعة (دائماً،كثيراً،أحياناً،نادراً).

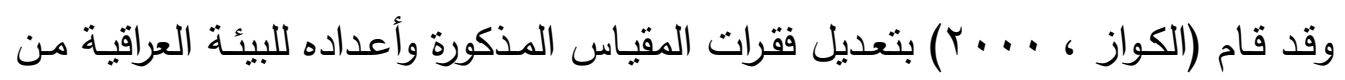

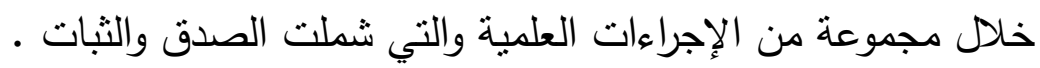
ومن أجل التأكد من صـلاحية المقياس المذكور لقياس السلوك القيادي لدى مدرسي التربية الرياضية في مركز مدينة الموصل فقد قام الباحثان بإجراء بعض التعديلات على فقراته

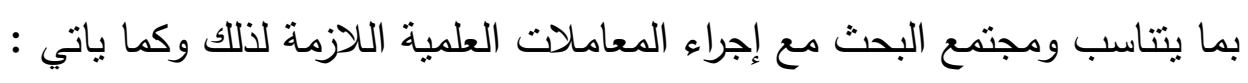
صدق المقياس

على الرغم من أن مقياس السلوك القيادي والذي قام بتعديله ( الكواز ، ... . ب) يتمتع

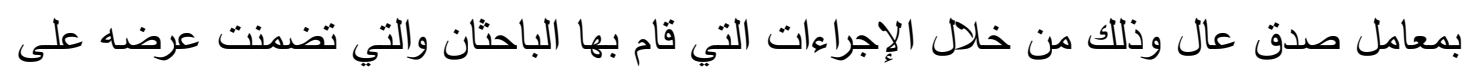

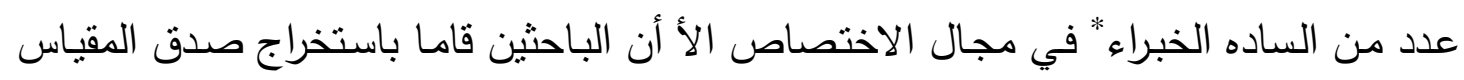

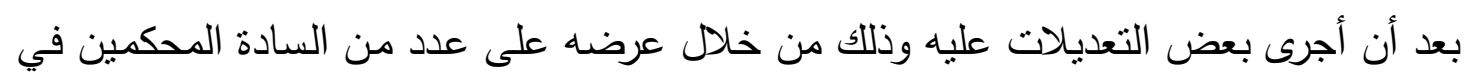

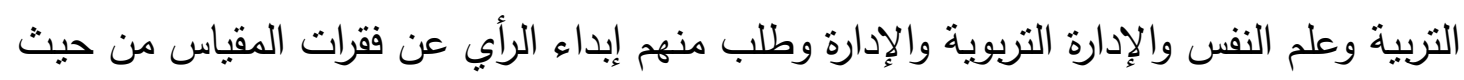
صلاحيتها لقياس السلوك القيادي لدى مدرسي التربية الرياضية ـ ويعد هذا الإجراء وسيلة مناسبة الإداء

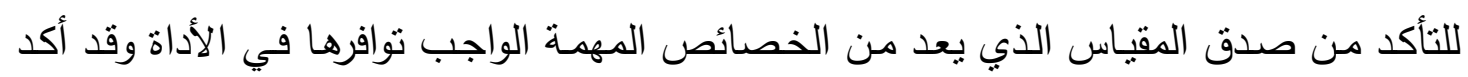

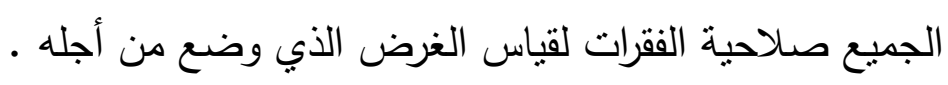

\begin{tabular}{|c|c|c|c|}
\hline 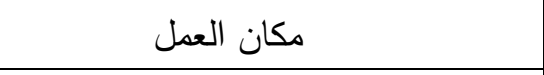 & القب العامي & الأسم & $ت$ \\
\hline كلية الأدارة والاقتصاد /جامعة الموصل & 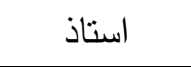 & | د.طارق شريف & -1 \\
\hline كلية التربية / جامعة الموصل & أستاذ & | د.راشد حمدون & $-r$ \\
\hline كلية التربية / جامعة الموصل & 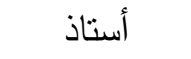 & | د. كامل عبد الحميد & r \\
\hline كلية الأدارة والاقتصاد / جامعة الموصل & أستاذ مساعد & | د.سرمد غانم & $-\varepsilon$ \\
\hline كلية التربية الاساسية جامعة الموصل & أستاذ مساعد & |د.جاجان جمعة محمد & -0 \\
\hline كلية التربية الرياضية / جامعة الموصل & أستاذ مساعد & |د. رياض أحمد إسماعيل & -7 \\
\hline كلية التربية / جامعة الموصل & أستاذ مساعد & |د. محمد علي عباس & $-V$ \\
\hline كلية التربية / جامعة الموصل & أستاذ مساعد & | د. أسامه حامد محمد & $-\wedge$ \\
\hline كلية التربية / جامعة الموصل & أستاذ مساعد & | د. سمير يونس محمد & -9 \\
\hline
\end{tabular}


إن الثبات يعني الاتساق في النتائج والأداة الثابتة هي التي نعطي النتائج نفسها أو نتائج متقاربة عند تكرار تطبيقها (ثورندايك وهيجن ، 1919 : VT ) وعليه فقد قام الباحثان باستخراج



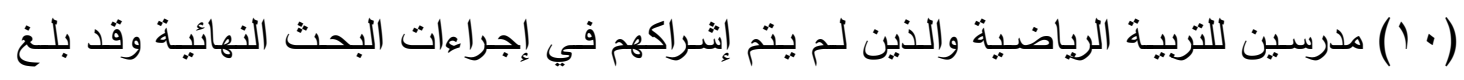

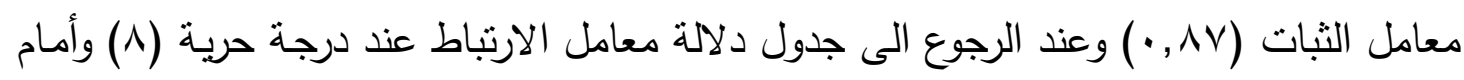

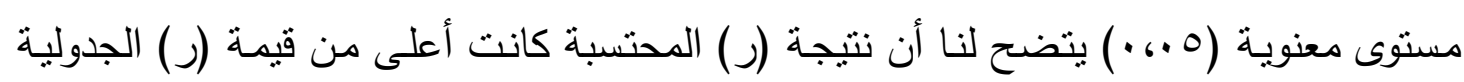

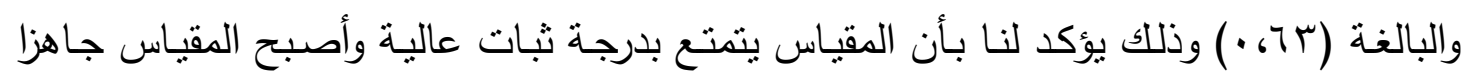

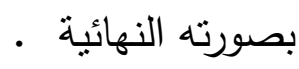

\section{r- مقياس الرضا عن العمل :}

نظراً لعدم وجود مقياس للرضـا عن العمل لمدرسي التربية الرياضية فقد قام الباحثان

بيناء مقياس الرضا عن العمل من خلال إتباع الخطوات الآتية :

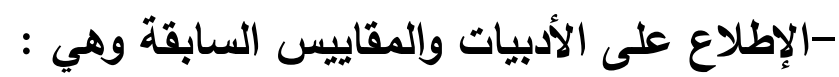

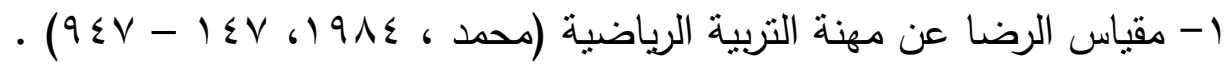

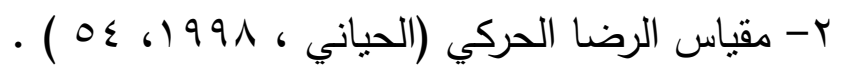

r- مقياس الرضا عن العمل لاى معلمي التربية الرياضية ( علاوي ، 991 19، 0 ) ) .

- إعداد الصيغة الأولية للمقياس :

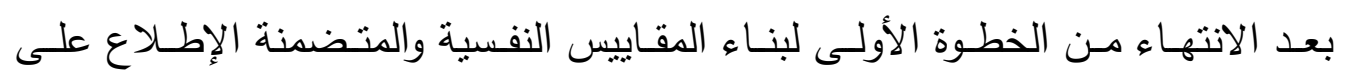
الأدبيات والبحوث والمقاييس السابقة فقد قام الباحثان بإعداد الصيغة الأولية من المقياس والتي التئي

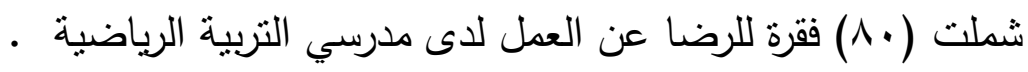

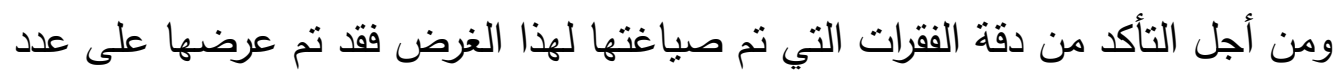

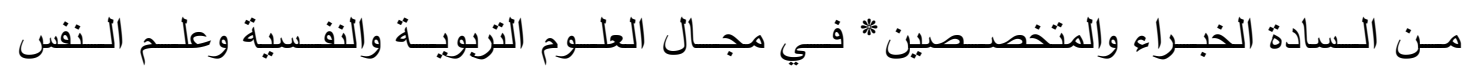

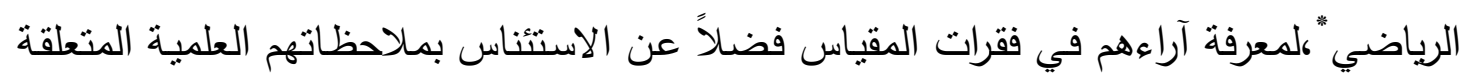

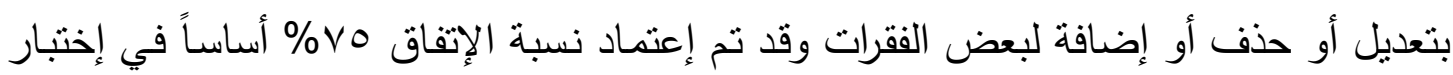

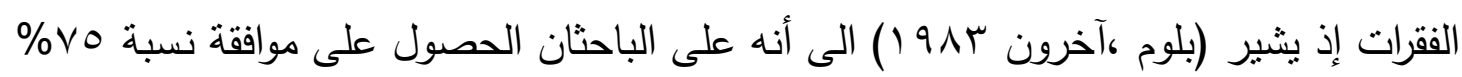

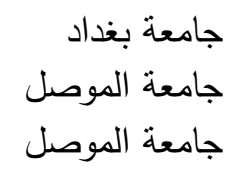

كلية التربية الرياضية كلية التربية كلية التربية الرياضية
أ. أ.محمد جسام عرب

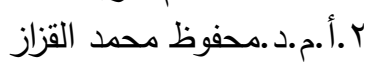
ع.م.د.زهير يحيى محمد علي 


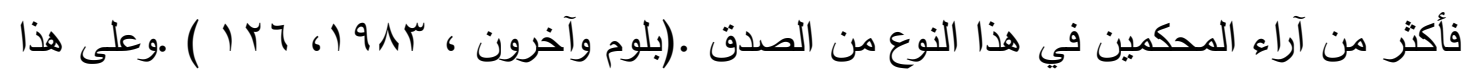

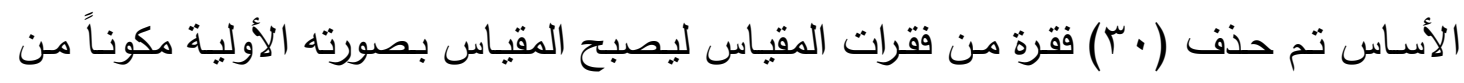

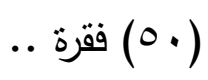

التجرية الاستطلاعية للمقياس

تم إجراء التجربـة الاستطلاعية على عينة قوامها ( • () مدرسين للتربية الرياضية وكان الغرض من إجراء التجربة ما بأتي :

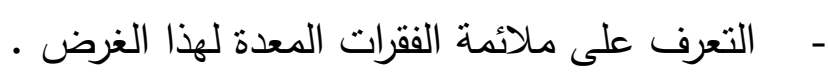
- - مدى وضوح الفقرات للبحوث ودرجة استجابته لها . - تجنب العبارات غير الواضحة وتبديلها بعبارات ملائمة .

التحليل الإحصائي للفقرات Items Analysis

من مواصفات المقياس الجيد إجراء التحليل الإحصائي لفقراته للتمييز بين الأفراد الذين

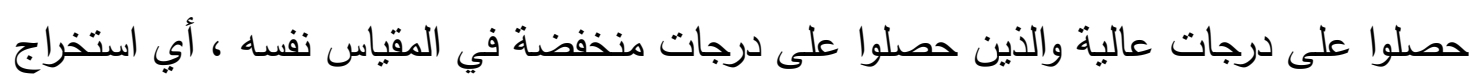

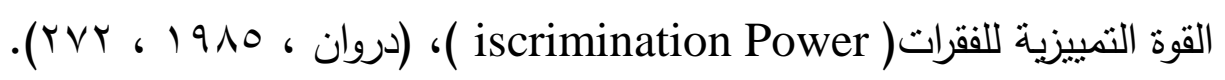
وقد تم إجراء التحليل الإحصائي بطريقتين : Internal Consistency Coefficient معامل الاتساق الاخلي

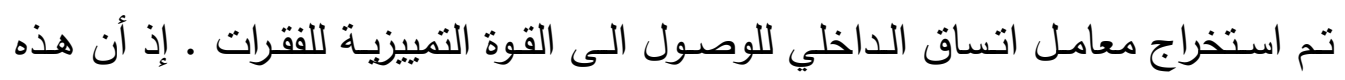

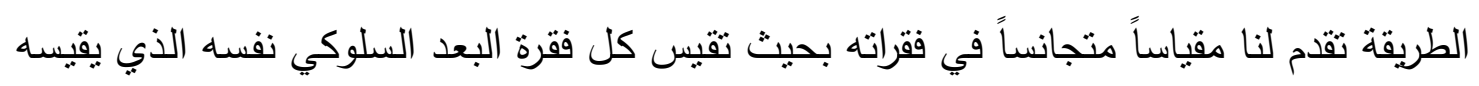

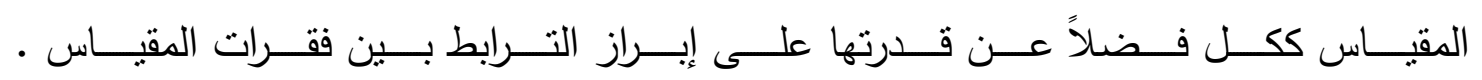

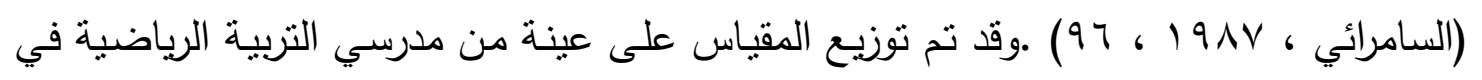

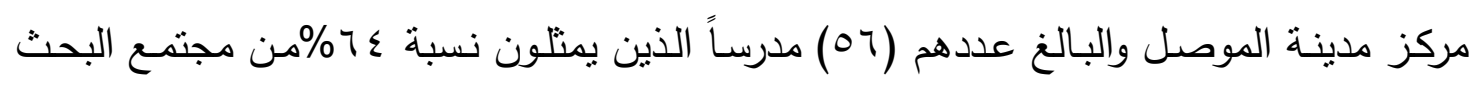

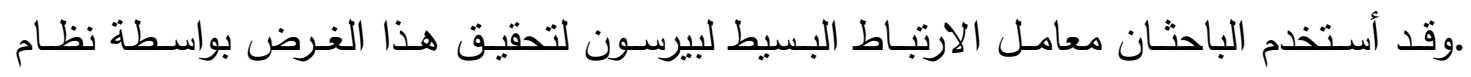
(SPSS)

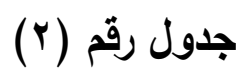


يبين معامل الارتباط بين فقرات المقياس والارجة الكلية باستخدام طريقة الاتساق الداخلي

\begin{tabular}{|c|c|c|c|}
\hline معامل التمييز & رقم الفقرة & معامل التمييز & رقم الفقرة \\
\hline ., & rt & $* \cdot, \cdot 1 r$ & 1 \\
\hline.,$r \leqslant r$ & TV & $*, Y Y T$ & r \\
\hline$* \cdot, \cdot \leq 99$ & rA & $\cdot, \varepsilon \leqslant \varepsilon$ & $r$ \\
\hline * & rq & $*$., , Y & $\varepsilon$ \\
\hline$* \cdot, \mid V \varepsilon$ & $r$. & $\cdot, r o s$ & 0 \\
\hline$* ., 10 r$ & r & $\cdot, \Sigma T V$ & 7 \\
\hline$* ., 1 \% q$ & rr & $\cdot, \varepsilon \leqslant r$ & v \\
\hline$* ., I Y$. & r &., $09 \varepsilon$ & $\wedge$ \\
\hline$* ., 191$ & $r \varepsilon$ & $* \cdot, I r \varepsilon$ & 9 \\
\hline$\cdot, \neg \wedge \varepsilon$ & ro & $* \cdot, \cdot \wedge$. & 1. \\
\hline.,$\Sigma T V$ & M & $* \cdot, 1,1$ & 11 \\
\hline$*, r M V$ & rV &., $01 Y$ & ir \\
\hline . YVq & rᄉ &., $01 Y$ & 15 \\
\hline$* ., .9$. & rq & $\cdot, 0 \wedge \varepsilon$ & $1 \leq$ \\
\hline$* \cdot, r \cdot Y$ & $\varepsilon$ & $\cdot, Y \wedge 9$ & 10 \\
\hline$* ., 199$ & «1 & $\cdot, \pi 11$ & 17 \\
\hline$* ., .99$ & $\varepsilon r$ & $* \cdot, I Y Y$ & IV \\
\hline צחוז, & $\varepsilon r$ &., 09 & 11 \\
\hline . rov & $\varepsilon \varepsilon$ & . & 19 \\
\hline$* \cdot, 1.7$ & so & $* \cdot, \cdot \leq 0$ & $r$. \\
\hline$* ., .79$ & $\leq 7$ & צדז, & rI \\
\hline$\cdot, \varepsilon \cdot 1$ & $\varepsilon V$ & . & rr \\
\hline$\cdot, r \vee A$ & $\leqslant \wedge$ & $\cdot, 717$ & rr \\
\hline$* \cdot, 1 \cdot v$ & $\varepsilon 9$ & $* \cdot, \cdot 4 \wedge$ & $T \leq$ \\
\hline., 094 & 0. & $\cdot, Y \wedge q$ & ro \\
\hline
\end{tabular}

* ققرة ضعيفة التمييز

يبين من الجدول رقم (r) أن قيم معامل الارتباط بين فقرات المقياس والدرجة الكلية

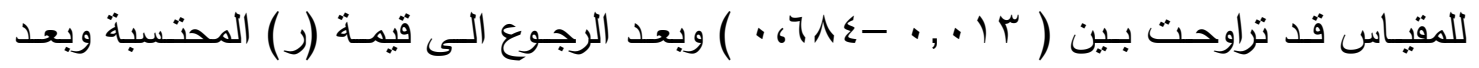




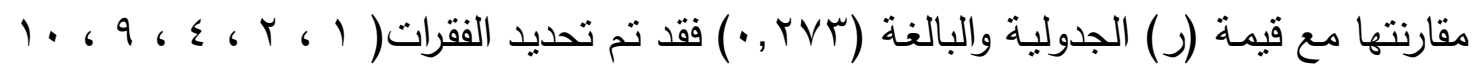

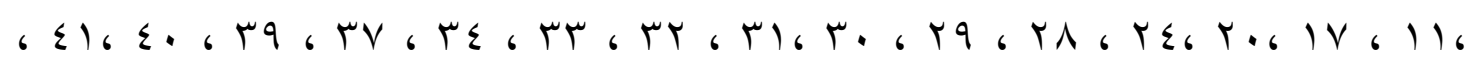
r بها أقل من قيمة (ر) الجدولية .

Contrasted Groups : بأسلوب المجموعات المتطرفة

تم استخدام أسلوب المجموعات المتطرفة للكثف عن الفقرات المميزة في بناء مقياس

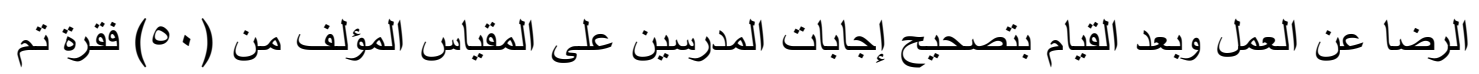



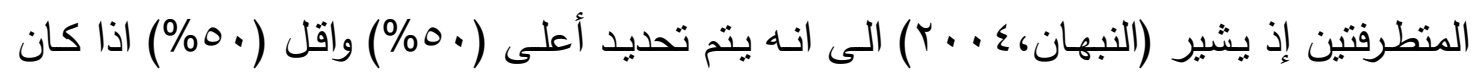

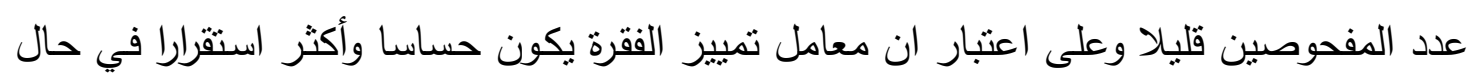

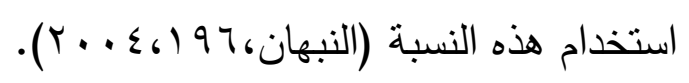

وقد تضمنت كل مجموعة (Y^) مدرساً واعتمدت قيمة (ت) الدالة إحصائياً مؤشراً لتمييز

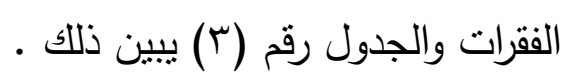

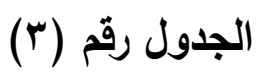

يبين قيمة (ت) المحسوية لفقرات مقياس الرضا عن العمل باستخدام المجموعات المتطرفة

\begin{tabular}{|c|c|c|c|}
\hline قيمة (ت) & رقم الفقرة & قيمة (ت) & رقم الفقرة \\
\hline $1, \cdot \leq \varepsilon$ & rT & محذوفة & 1 \\
\hline$r, \varepsilon \leqslant q$ & rV & محذوفة & $r$ \\
\hline محذوفة & rA & $1, r \leq r$ & $r$ \\
\hline محذوفة & rq & محذوفة & $\varepsilon$ \\
\hline محذوفة & $r$. & $*, 00 r$ & 0 \\
\hline محذوفة & r & $r, .1 \mathrm{~V}$ & 7 \\
\hline محذوفة & rT & T,YTI & $v$ \\
\hline محذوفة & بr & $r, 01 \mathrm{~V}$ & $\wedge$ \\
\hline محذوفة & $r \varepsilon$ & محذوفة & 9 \\
\hline$r, 0 \wedge \Lambda$ & ro & محذوفة & 1. \\
\hline r.VOT & ru & محذوفة & 11 \\
\hline محذوفة & rv & $\cdot, v \leqslant$. & ir \\
\hline
\end{tabular}




\begin{tabular}{|c|c|c|c|}
\hline $1, v \leq \varepsilon$ & rᄉ & $1, \wedge \cdot \varepsilon$ & Ir \\
\hline محذوفة & rq & $\cdot, 9 \leq 9$ & $1 \varepsilon$ \\
\hline محذوفة & $\varepsilon$ & $r, \Gamma) \wedge$ & 10 \\
\hline محذوفة & « & $r, V \backslash \leq$ & 17 \\
\hline محذوفة & $\varepsilon r$ & محذوفة & IV \\
\hline$r, 909$ & $\varepsilon r$ & 1,879 & 11 \\
\hline r, r. & $\varepsilon \varepsilon$ & גוז, & 19 \\
\hline محذوفة & $\leqslant 0$ & محذوفة & $r$. \\
\hline محذوفة & $\leq 7$ & r,人тr & YI \\
\hline $1,9.9$ & $\varepsilon V$ & $Y, Y \leq 1$ & YY \\
\hline $1, \varepsilon \cdot 7$ & $\varepsilon \wedge$ & r, & r \\
\hline محذوفة & $\leqslant 9$ & محذوفة & $r \varepsilon$ \\
\hline $1, \leq \leqslant 1$ & 0 & $1, \times 11$ & ro \\
\hline
\end{tabular}

* قرة ضعيفة التمييز

يبـين مــن الجـدول رقــم (ب) أن القـيم التائيــة لفقـرات المقيــاس تراوحــت بــين

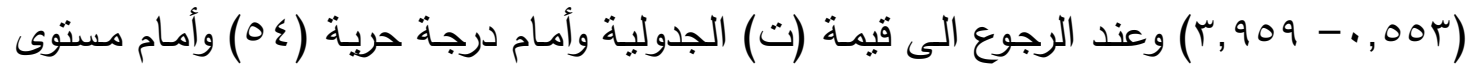

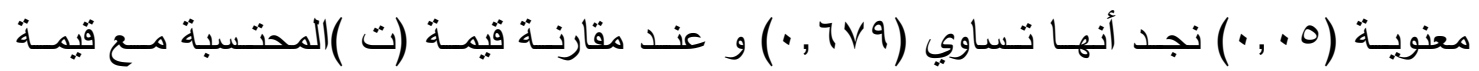
(ت)الجدولية نجد ان الفقرة (0 ) تعد فقرة ضعيفة التمبيز بأسلوب المجموعات المتطرفة. ونظراً لاتفاق طريقتي الاتساق الداخلي والمجموعات المتطرفة على أن الفقرات ( (، r ، ؛ ، 0 ، ، 9

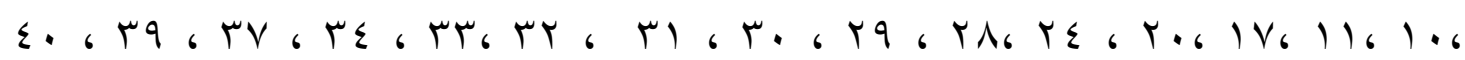

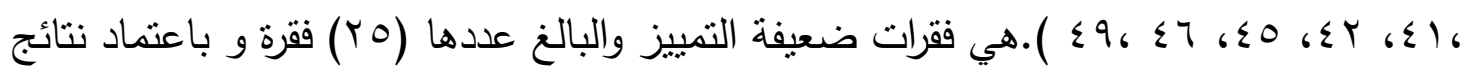
التحليل الإحصائي بكلا الطريقتين وبعد حذف الفقرات غير المميزة أصبح المقياس مؤلفاً بصيغته النهائية من (ب0) فقرة .

\section{الصدق المرتبط بالمحك}

يقصد بالصدق المرتبط بالمحك قدرة المقياس على التتبوء بسلوك الفرد في مواقف محددة

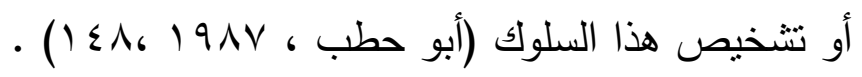
فقد قام الباحثنان بإجراء الصدق المرتبط بالمحك وذلك من خلال قيامه بتوزيع مقياس الرضـا عن العمل لدى معلمي التربية الرياضية (عـلاوي ، 9 9 1 ) ومقياس الرضـا عن العمل الذي قام ببناءه الباحثان على ( • () من مدرسي التربية الرياضية في أقضية محافظة نينوى وبعد 


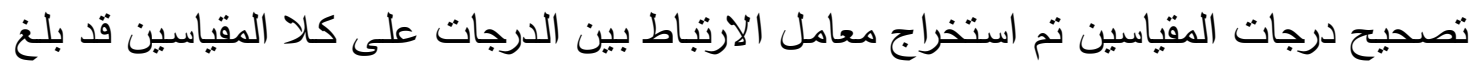

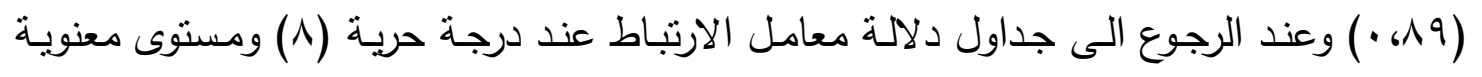



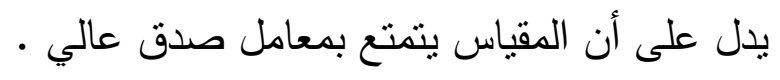
الثبات

يقصد بالثبات دقة المقياس في القياس أو الملاحظة وعدم تتاقضه مع نفسه واتساقه فيما

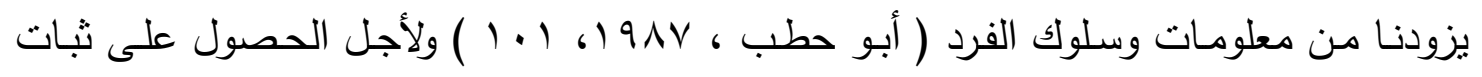

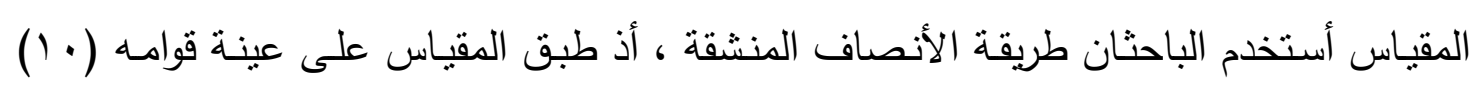

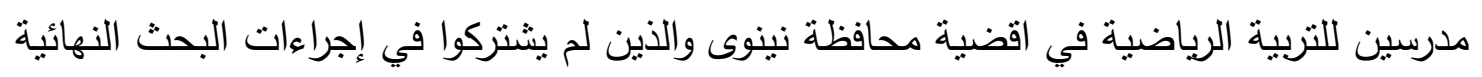

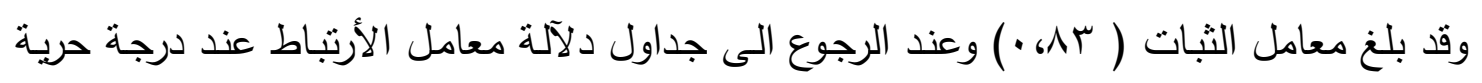

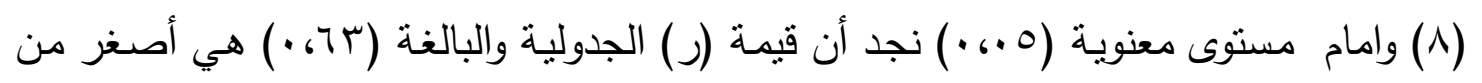

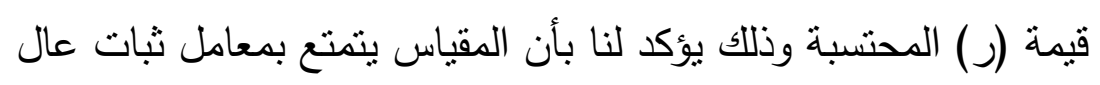

\section{الصورة النهائية للمقياس}

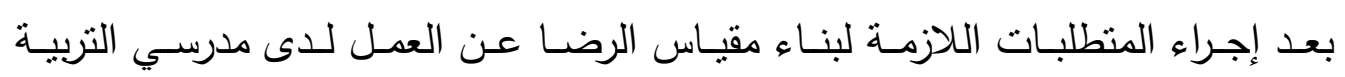

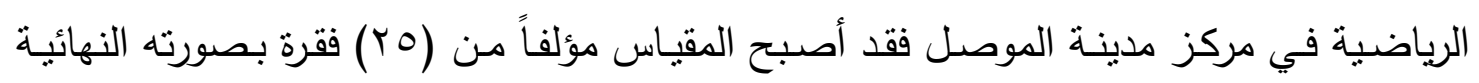
تكون الإجابة علبه من خلال ثلاث بدائل هي (دائماً ، احياناً، نادراً) .

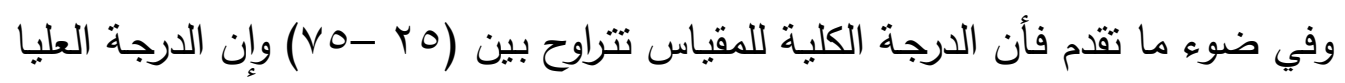

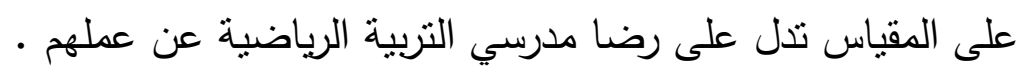

\section{التطبيق النهائي للبحث}

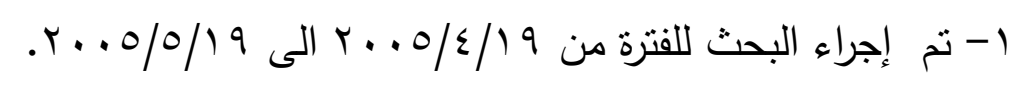

r-بعد أن أجرى الباحثنان جميع الإجراءات العلمية المتعلقة بإعداد مقياس السلوك القيادي وبناء

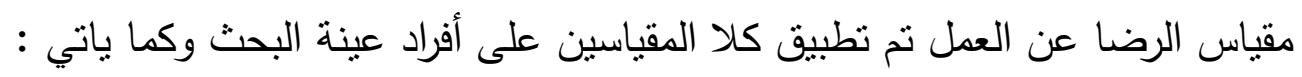
ا ـ توزيع مقياس السلوك القيادي على مدراء المدارس في الجانب الايمسن من مركز مدينـة

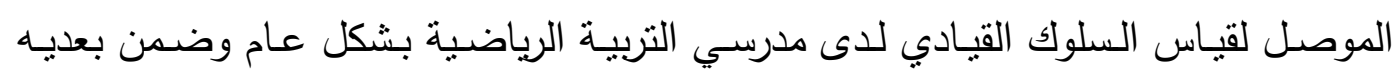

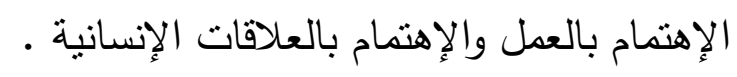


r. ت توزيع مقياس الرضا عن العمل لدى مدرسي التربية الرياضية على المدرسين في الجانب

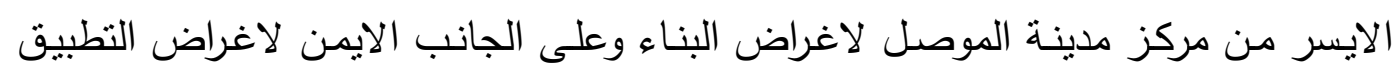

$$
\text { وعلى نفس المدرسين والعاملين في الادارات الواردة في الفقرة (1). }
$$

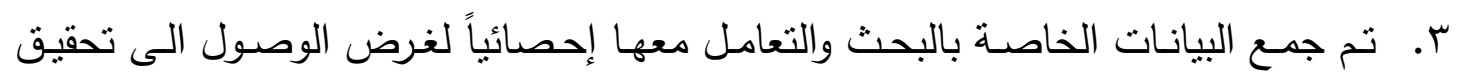

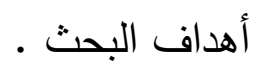

\section{الوسائل الإحصائية}

الوسط الحسابي .الانحراف المعياري .النسبة المئويـة .معامل الإرتباط البسيط .تحليل

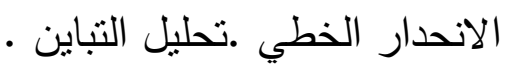

\section{عرض النتائج ومناقشتها}

سيتم عرض النتائج ومناقشتها في ضوء البيانات الاحصائية التي تم الحصول عليها من

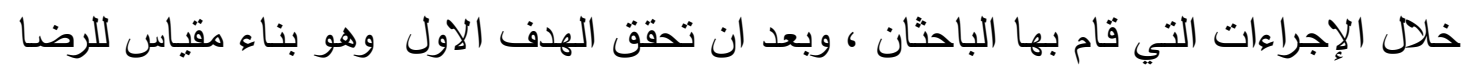



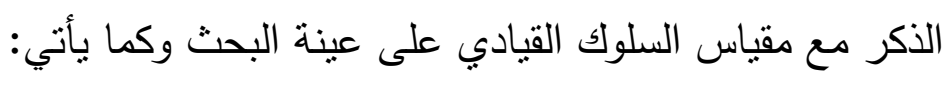

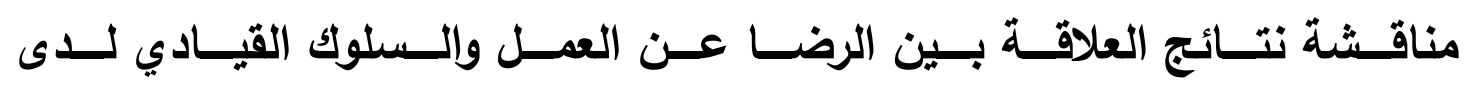
مدرس التربية الرياضية.

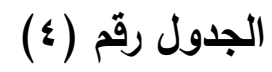

يبين تحليل تباين الانحدار بين الرضا عن العمل والسلوك القيادي لدى مدرسي التربية الرياضية

\begin{tabular}{|c|c|c|c|c|}
\hline قيمة (ف) & متوسط المربعات & درجة الحرية & مجموع المربعات & التباين \\
\hline \multirow{3}{*}{ סזו,דזי } & $1 \cdot \wedge, \wedge \varepsilon 1$ & 1 & $1 \cdot \wedge, \wedge \leq 1$ & الانحدار \\
\hline & $\varepsilon, 7.0$ & $r q$ & $1 \pi r, 0 \leq V$ & البواقي \\
\hline & & $r$. & rEY,rAV & المجموع \\
\hline
\end{tabular}

يــين مـن الجـدول (ع) ان قيمــة (ف) المحتسبة باسـتخدام تحليـل انحـدار تـساوي

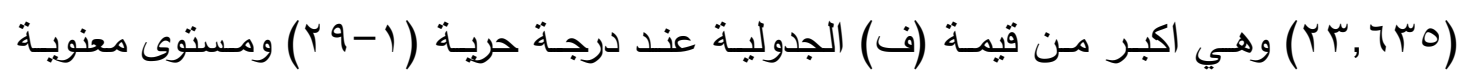

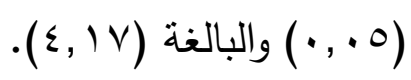




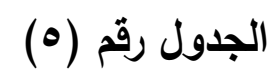

يبين معامل الارتباط ومعامل التحديد للعلاقة بين الرضا عن العمل والسلوك القيادي لاى مدرسي التربية الرياضية

\begin{tabular}{|c|c|c|}
\hline الخطأ القياسي & معامل التحديد & معامل الارتباط \\
\hline$r, 1 \leq 09 \leq$ & $\cdot, \leq \leqslant 9$ & $\cdot, T V$. \\
\hline
\end{tabular}

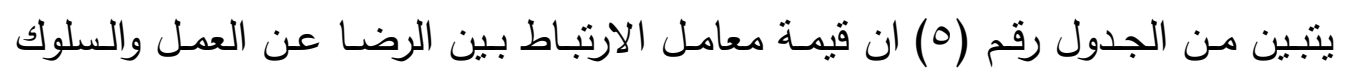

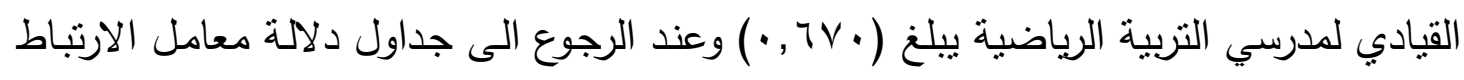

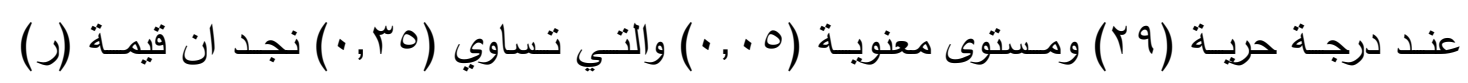

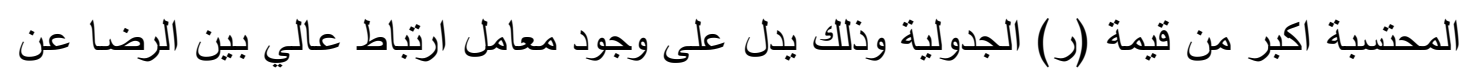

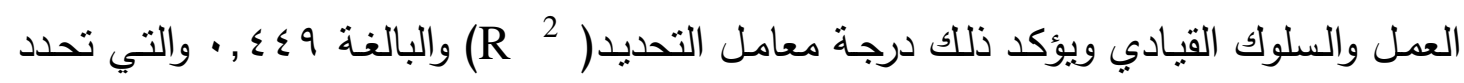
طبيعة هذه العلاقة وذلك ما يجعلنا نرفض الفرضية الصفرية ونقبل الفرضية البديلة. ويعزو الباحثان النتائج الحالية الى طبيعة العلاقة القائمة بين السلوك القيادي لدرسي لئسي التربية الرياضية ودرجة رضاهم عن العمل في ان درجة الرضا يمكن ان تعد مؤشرا علميا دقيقا

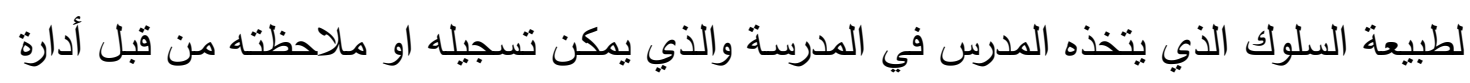

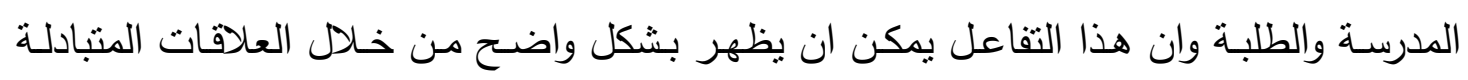
واحترام الراي ومراعاة مشاعر الآخرين وباعتماد بعدي السلوك القيادي المهتم بالعدل والمهنت بالعلاقات الإنسانية وفي ذلك يؤكد رامزدين (Ramsden,1983) الى ان النمط القيادي المهنم

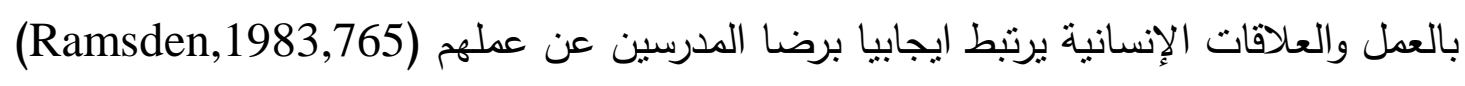

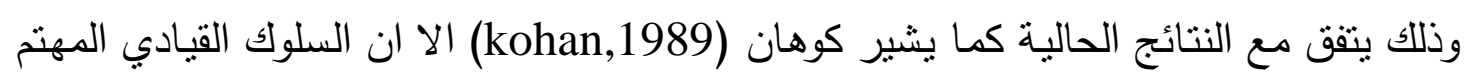

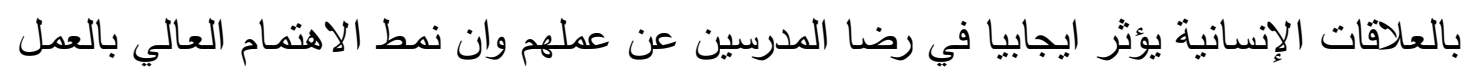

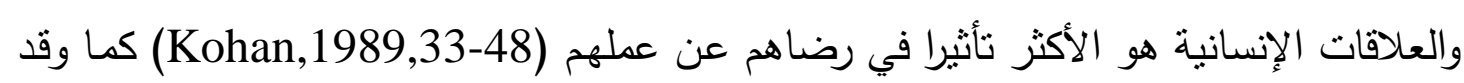

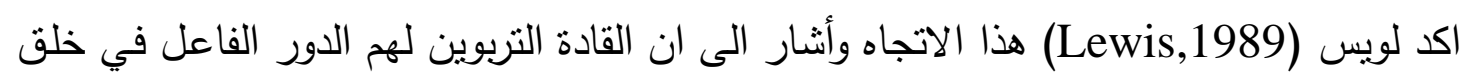
رضا عالي عن العمل لدى المرؤوسين (107-Lewis,1989,91) وذلك يتفق ايضا مـع النتائج التي جاء بها (الدليمي ، .99 (19) والتي اثار الى وجود علاقة ايحابية بين النمط القيادي ورضا المدرس عن عمله.

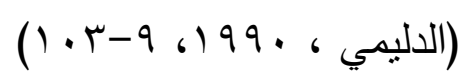

وبهذا الصدد فان الباحثنان في تفسيره النتائج الحاليـة من خـال تبنيه لنظريـة فردريك

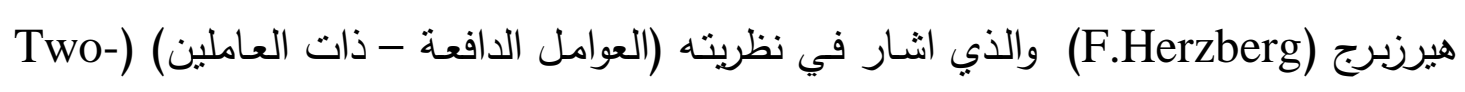


Factor Theory

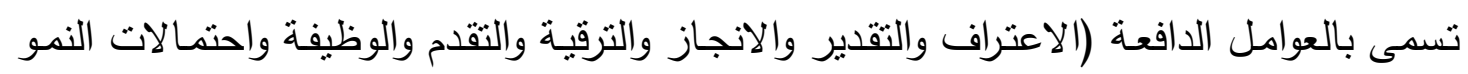

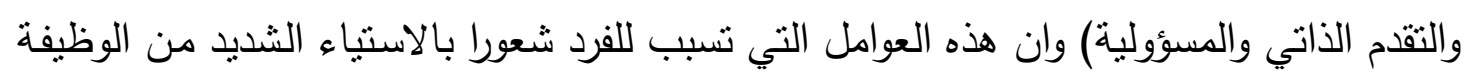

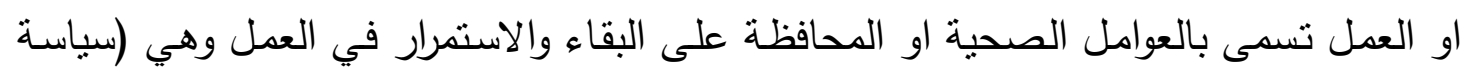

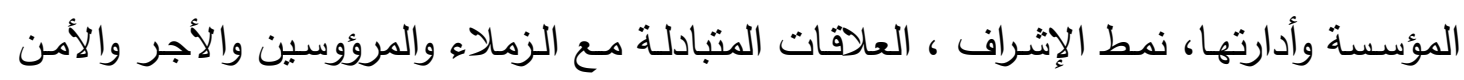

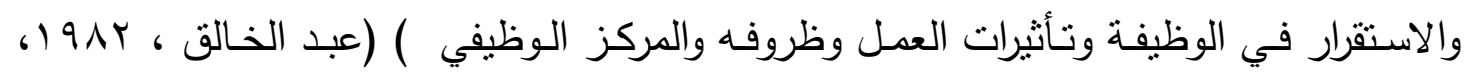

وفي ضوء ذلك يمكن ان يفسر الباحثان النتائج الحالية الى ان زيادة الأجور وتوفر

الفرص المناسبة للشعور بالمكانة والاعتراف بالجهد والتقدير قد ساهم والى حد كبير في ظهور

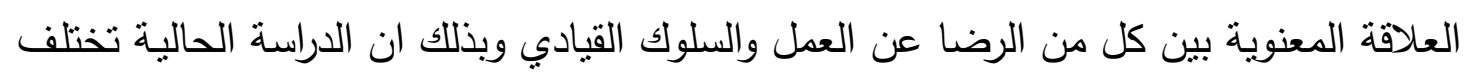

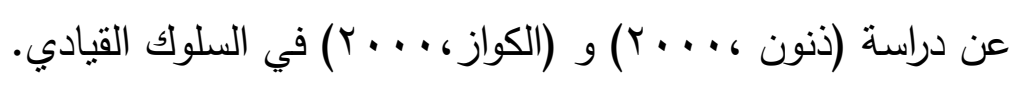

\section{الاستتناجات:}

ا فاعلية مقياس الرضا عن العمل لدى مدرسي التربية الرياضية والذي قام الباحثان ببناءه في

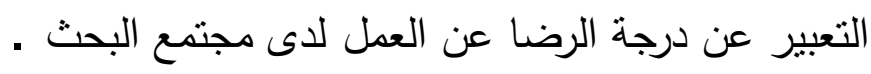

r. هناك علاقة ذات دلالة معنوية بين السلوك القيادي والرضا عن العمل لدى مدرسي التربية الرياضية في مركز مدينة الموصل.

ك. ان درجـة الرضـا عن العمل لـى مدرسـي التربيـة الرياضية لاتعبـر عن طبيعـة العلاقـات الانسانية التي تمثل جانبا مهما من سلوكهم القيادي داخل المدرسة.

ع.ان درجة الاهتمام بالعمل لدى المدرسين من خلال سلوكهم القيادي في الددرسة ترتبط معنويا مع درجة الرضا عن العمل.

التوصيات

1. العمل على تتمية درجة الاهتمام بالعمل والعلاقات الإنسانية بين مدرسي التربية الرياضية لضمان رضاهم عن العمل الذي يقومون به من اجل أعداد الجيل الجديد. 


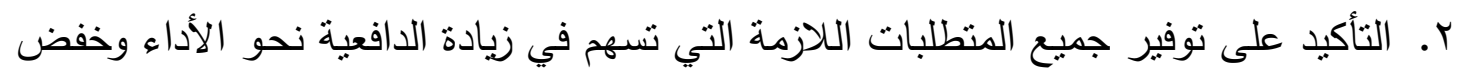

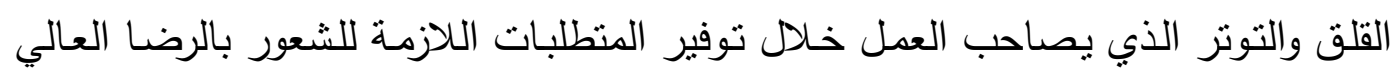
من خلال النواتج الايجابية التي تقابل العمل الذي يؤدونه ـ r. توفير الفرص اللازمة لنطوير المعارف والخبرات لدى العاملين في المجال التزبوي لاسيما

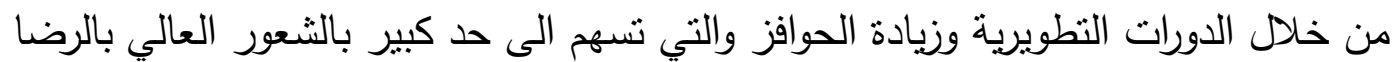

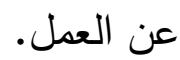

\section{المصادر العربية والأجنبية}

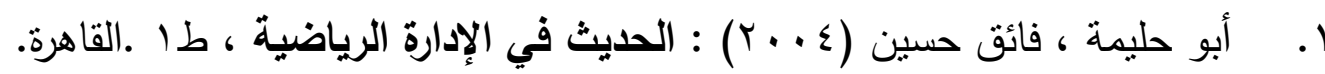
r. ابو حطب ، فؤاد (91v (1): التقويم النفسي ، طس، مكتبة الانجلو الدصرية ، القاهرة.

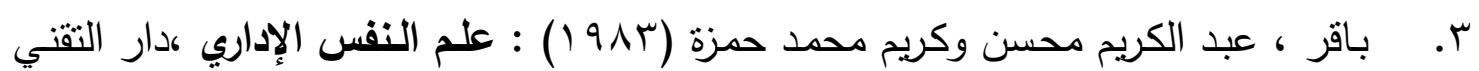

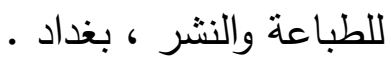

ع. بلوم بنيامين وآخرون (r/911) : تقييم الطالب التجميعي والتكويني ، ترجمة محمد أمين



ه. ثورندايك ، روبرت واليزابيث هيجن (919 ()): القياس والتقويم في علم النفس والتربية، ترجمة : عبد الله زيد الكيلاني و عبد الرحمن عدس ، مركز الكتب الأردني ، عمان. 7. جراي ، جيري ل (919 (1) : الإثراف مدخل علم السلوك التطبيقي لأداره الناس ، ترجمة

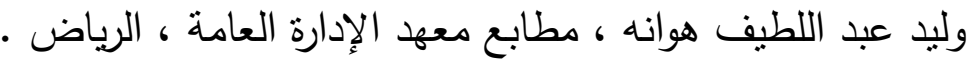

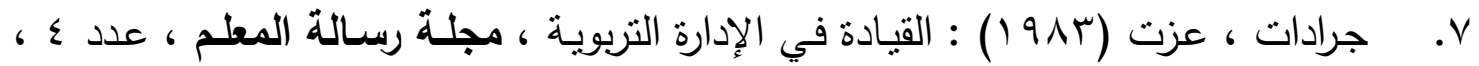

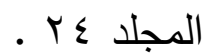

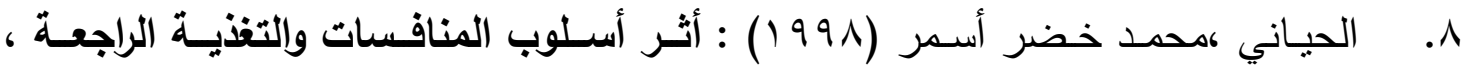


الرياضية ، أطروحة دكتوراه غير منشورة.

9. الدرة ، عبد الباري وآخرون (ـ99 1) : الإدارة الحديثة ، المفـاهيم والعمليـات ، مطبعة

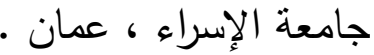

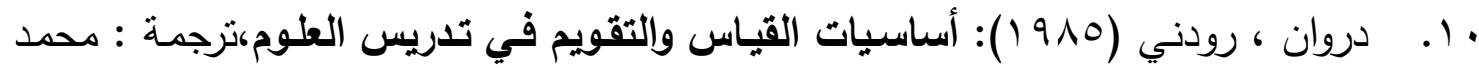
سعيد صبار وآخرون ، دار الامل ، الاردن. 


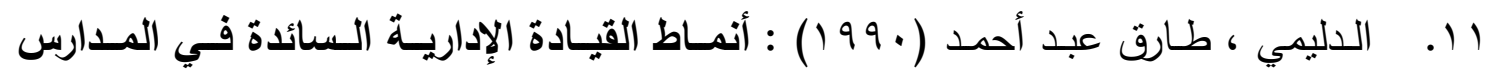

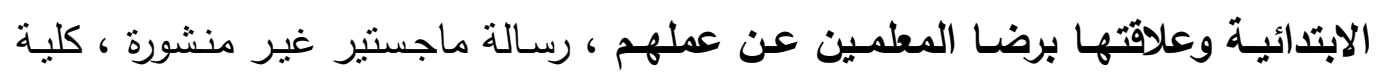

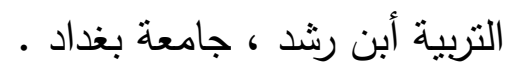

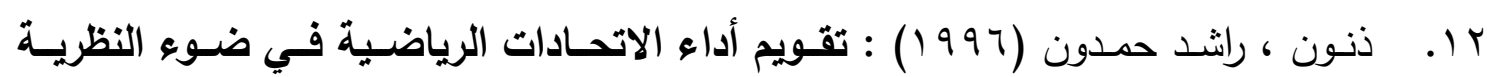

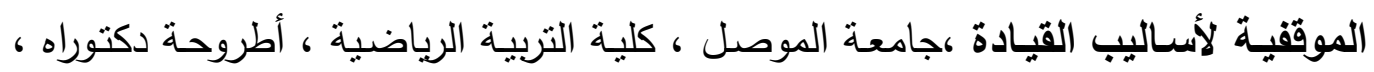




للبحوث التريوية،المجلد السابع ، العدد الثاني. باني.

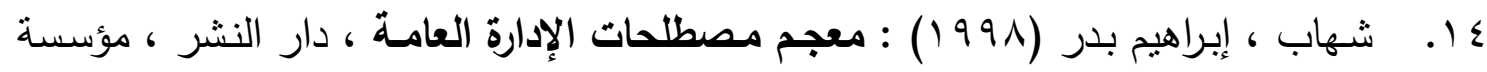

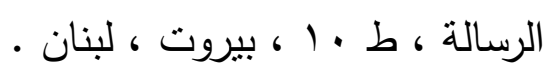

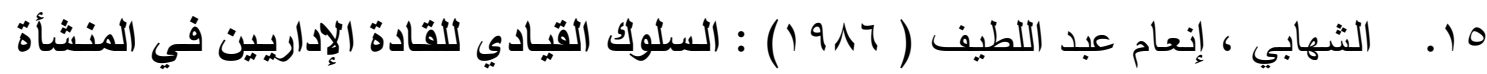
العامة للخياطة ، المركز القومي للبحوث الاجتماعية والجنائية ، بغداد .

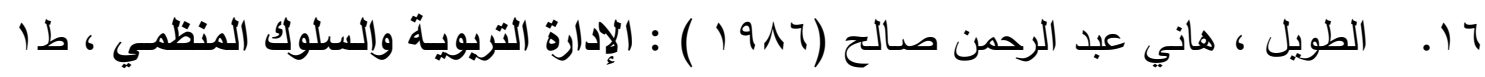

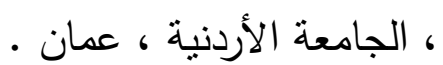

V V . عاثشور ، أحمد صقر (71911) : إدارة القوى العاملة ، دار المعرفة الجامعية ، الإسكندرية

11. عبد الخالق ، ناصيف (r/911) : الرضا وأثثره على إنتاجية العمل ، المجلة العربية للإدارة

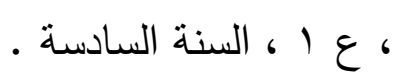

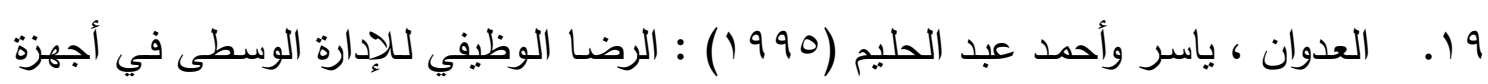

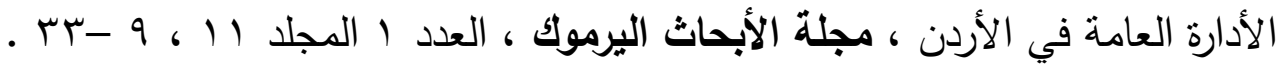

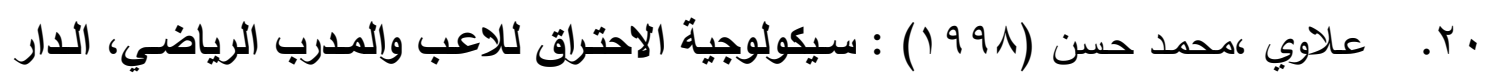

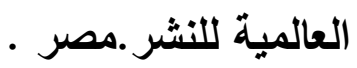

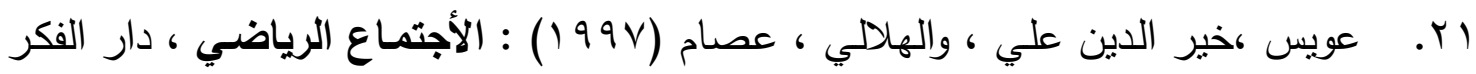

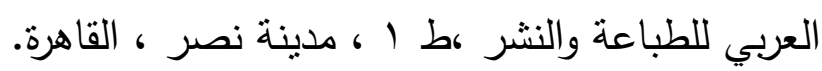

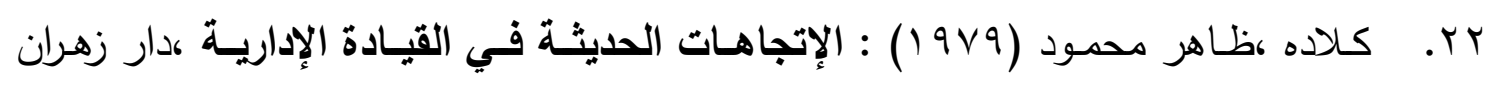



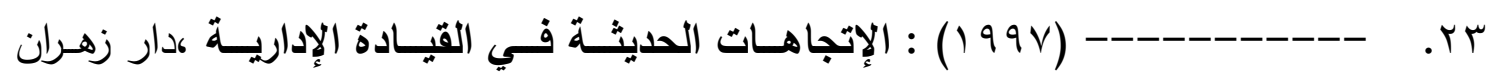

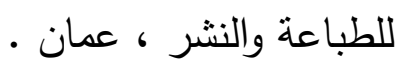




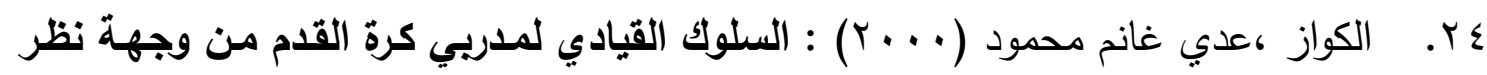
اللاعبين وفقاً لمركز التحكم لأنديـة الارجهة الأولى ،راسلة ماجستير غير منشورة، كلية التربية الرياضية ، جامعة الموصل.

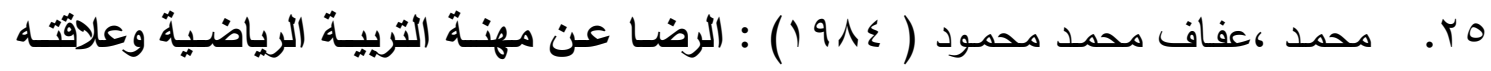

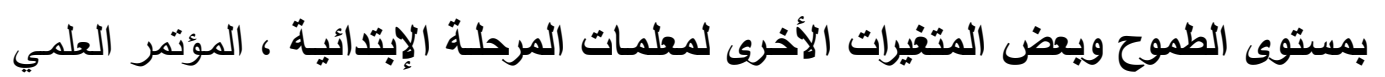

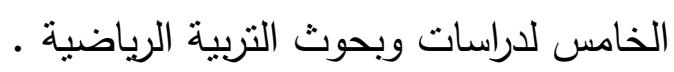

ج ب. النبهان ،موسى (ع . . r) : أساسيات القياس في العلوم السلوكية ،الطبعة العربية الاولى

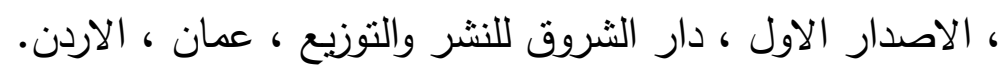

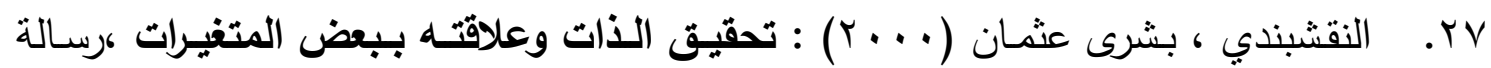

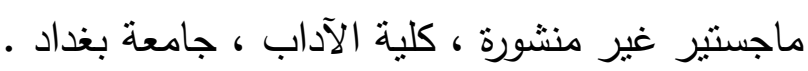

28. Herbert, Theodore . ( 1981):dimensions of Organizational Behavior, $2^{\text {nd }}$ ed. , Macmillan Publishing, Co. Inc, New York .

29. Kohn , Alan : (1989)Interactions Between Superintendent Leader Behavior and Locus of Control on Job Satisfaction as Perceived by Vocational teachers . D.A.I, Vol.13, No.4.

30. Koontz Harold and Others (1980), Management, $7^{\text {th }}$ ed. , McGraw Hill London .

31. Lewis , Marjoride : (1989) effective Leadership Strategies for Community College President, D.A.I. , Vol.13 . No.1.

32. Lorenz, peter et al (1997) . Management Quality and Competitiveness $2^{\text {nd }}$ ed. , McGraw Hill Company .

33. Ramsden Patricia .(1983) : the Releationship Between Part-Time Faculity Job Satisfaction and Perception of Division Chair persons Leadership Behavior in Community Colleges D.A.I., Vol. 45 , No.03,.

34. Steers Richard M. And Porter L.W.(1983) . Motivation and work Behavior, McGraw Hill Company New York.

35. Tannhill, Robert E( 1970) . Motivation and Management Development, Butterworth London .

36. Tanninbaum R. \& Shmidt W (1985 ) "Retrospective Commentary on How to choose a Leadership Patters" Academy of Management Review Vol.8. No,2 . 